\title{
Nonlinear Response of Laterally Loaded Piles and Pile Groups
}

\author{
Wei Dong Guo \\ School of Engineering \\ Griffith University, Gold Coast Campus, Australia
}

\begin{abstract}
In spite of extensive studies on laterally loaded piles carried out over years, none of them offers an expedite approach as to gaining nonlinear response and its associated depth of mobilisation of limiting force along each pile in a group. To serve such a need, elastic-plastic solutions for freehead, laterally loaded piles were developed recently by the author. They allow the response to be readily computed from elastic state right up to failure, by assigning a series of slip depths, and a limiting force profile (LFP). In this paper, equivalent solutions for fixed-head single piles were developed. They are subsequently extended to cater for response of pile groups by incorporating p-multipliers.
\end{abstract}

The newly established solutions were substantiated by existing numerical solutions for piles and pile groups. They offer satisfactory prediction of nonlinear response of all the 6 single piles and 24 pile groups investigated so far after properly considering the impact of semi-fixed head restraints. They also offer the extent to ultimate state of pile groups via the evaluated slip depths. The study allows ad hoc guidelines to be established for determining input parameters for the solutions. The solutions are tailored for routine prediction of nonlinear interaction of laterally loaded fixed-head piles and capped pile groups.

Key words: pile groups, closed-form solutions, nonlinear response, lateral loading, soil-structure interaction 


\section{Introduction}

Laterally loaded piles may entail large deformation in extreme events such as ship impact, earthquake etc. These piles are often cast into a pile cap that restrains pile-head rotation, but allows horizontal translation. Study on this type of capped piles is of practical significance.

Generally speaking, maximum (limiting) resistance along a pile is gradually mobilised downwards from mudline, with increase in lateral pile-head loads. This limiting force is the sum of the passive soil resistance acting on the face of the pile in the direction of soil movement, and sliding resistance on the side of the pile, less any force due to active earth pressure on the rear face of the pile. The profile of the net limiting force per unit length with depth (i.e. the $p_{u}$ profile) is referred to as LFP [1].

The pile-soil interaction has been preponderantly characterized using a series of independent (uncoupled) springs distributed along the shaft. These springs may be coupled via a membrane as derived from variational approach $[2,3]$. The model based on the coupled springs compares well with numerical approaches for elastic medium $[2,3]$. It was then extended to cater for elastic-plastic response [1] (see Figure 1) by adding a slider in series with each spring along the pile shaft. The springs and the membrane are in action upon loading. The sliders are active only when the local forces per unit length reach the limiting values of $p_{u}$. The springs-slidersmembrane model allows elastic-plastic closed-form solutions for free-head (FreH), single piles [1] to be developed. The solutions are sufficiently accurate for modelling nonlinear pile-soil interaction compared to experimental observation, and rigorous numerical approaches. They have various advantages over early work [4] as outlined previously [1]. In particular, the nonlinear response is captured by the $\mathrm{p}_{\mathrm{u}}$ profile and the depth of full mobilisation (termed as slip depth, $x_{\mathrm{p}}$ 
under a pile-head load $P$ ) of the $\mathrm{p}_{\mathrm{u}}$, along with a subgrade modulus $(k)$ that embraces the effect of pile-soil relative stiffness, head and base conditions on the pile response.

Study to date allows one to perceive the following facts.

- Direct use of fixed-head, elastic solutions generally overestimates maximum bending moment and deflection of piles that are cast into a reinforced concrete cap, against measured data, showing the impact of partially fixed-head (semi-fixed head) conditions[5].

- Nonlinear response of piles is by and large dominated by the $\mathrm{p}_{\mathrm{u}}$ profile (with negligible coupled effect at a high load level [1]) and the slip depth, $x_{\mathrm{p}}$. The $\mathrm{p}_{\mathrm{u}}$ profile alters significantly with pile-head restraints [6]. The slip depth is essential to assessing extent of site investigation and identifying failure mode of individual piles in a group.

- Predicting maximum bending moment requires considering loading details and head restraint.

- Load distributions among piles in a group have not been satisfactorily mimicked using numerical approaches such as finite element method (FEM), and finite difference approach (FDA), etc [7]. In contrast, the distributions were well revealed using numerical methods underpinned by the less rigorous concept of p-multipliers [8]. And finally

- There is not an expedient method for evaluating nonlinear response and the slip depth mobilised along each pile in a group.

These unclarified points prompt the current study aimed at the following objectives.

- Developing elastic-plastic closed-form solutions for a laterally loaded, fixed-head (FixH) pile.

- Establishing a pragmatic approach for predicting nonlinear response of pile groups, which caters to semi-fixed head (free-standing) conditions as well.

- Examining the impact of pile-head restraints, group interaction, and the failure mode. 
- Formulating preliminary guidelines for determining the input parameters $k$ and $\mathrm{p}_{\mathrm{u}}$

The solutions and the approach were implemented into a spreadsheet program called GASLGROUP to facilitate numeric computations. The solutions were substantiated using FEM results regarding a single pile in sand. The approach is evolved from the solutions for the single piles and by introducing pile-pile interaction via utilising the p-multipliers. It was calibrated using available numerical FEM and FDA results for a few typical pile groups. GASLGROUP was used to study 6 single piles and 24 pile groups in sand and clay against measured nonlinear responses, from which the ad hoc guidelines are proposed. Four typical examples are elaborated to show validity and use of the current approach.

\section{Overall Solutions for A Single Pile}

Figure 1 shows the springs-sliders-membrane model for a laterally loaded pile embedded in a non-homogeneous elastoplastic medium. The pile has no rotation at head level. The pile-soil system is simulated using the uncoupled (plastic zone) and coupled (elastic zone) load transfer models [1]. It is underpinned by the five hypotheses /features that are recapitulated in Table I. With regard to Figure 1, it is noted that

- The Winkler springs have an identical subgrade modulus $k$. They are linked by a membrane having a fictitious tensile force $N_{\mathrm{p}}$.

- The limiting force per unit length on each slider is $\mathrm{p}_{\mathrm{u}}$ beyond which pile-soil relative slip occurs. The slip starts only from mudline and expands downwards with increase in loads.

- The pile length in elastic zone exceeds a critical length $L_{\mathrm{c}}$ (length $L_{\mathrm{c}}$ is given in next section).

Deviations from the hypotheses generally have negligible effect on the predicted pile response [1]. 


\subsection{Coupled load transfer model (elastic state)}

Figure 1 can be reduced to the coupled fixed-head, pile-soil system for elastic state given $x_{\mathrm{p}}=0$. Applying a variational approach to the elastic system, relevant expressions were developed previously [2], which are outlined in Table II.

Table II Load transfer model for single piles [1]

Parameters $\alpha_{\mathrm{o}}, N_{\mathrm{g}}$, and $\mathrm{n}$ for LFP

(1) $p_{\mathrm{u}}$ is effective to the slip depth $x_{\mathrm{p}}$. Soil strength parameters $\mathrm{s}_{\mathrm{u}}$ (undrained shear strength), $N$ (blow count of SPT), and $\phi^{\prime}$ (effective angle of friction of soil) are calculated as the average values over the maximum $x_{\mathrm{p}}$. This max. $x_{p}$ initially is taken as $8 d$ for prototype piles, and $20 d$ for model piles

(2) FreH piles in cohesive soil: $\alpha_{\mathrm{o}}=0.05-0.2 \mathrm{~m}, N_{\mathrm{g}}$ $=0.6-4.8$ (average 1.6), and $n=0.7 \sim 1.7 . \mathrm{n}=0.7$ for a uniform strength profile; whereas $n=1.5$ -
$\mathrm{G}_{\mathrm{s}}, L_{\mathrm{c}}, k$, and $N_{\mathrm{p}}$ for elastic response

(a) $G_{s}=(25-340) s_{u}$ with an average of $92.3 s_{u}$. $G_{s}=(0.25-0.62) N(\mathrm{MPa})$ with an average of $0.5 N(\mathrm{MPa})$. The parameters $\mathrm{s}_{\mathrm{u}}$ and $N$ are calculated as the average values over the critical pile length $L_{\mathrm{c}}$ given by

(b)

$$
\frac{L_{c}}{r_{o}}=2.1\left[\frac{E_{p}}{G_{s}}\right]^{0.25}
$$


1.7 for a sharp increase strength profile (e.g. in stiff clay), otherwise, $\mathrm{n}$ is in the middle range (e.g. for a multi-layered soil). Given $n=\alpha_{0}=0$, the $\mathrm{p}_{\mathrm{u}}$ reduces to $\mathrm{s}_{\mathrm{u}} N_{\mathrm{g}} \mathrm{d}$, with $N_{\mathrm{g}}=2-4$ [9].

(3) FreH piles in sand: $N_{\mathrm{g}}=s_{\mathrm{g}} K_{\mathrm{p}}{ }^{2}, \alpha_{\mathrm{o}}=0$, and $n=$ 1.7 , where $K_{\mathrm{p}}=\tan ^{2}\left(45^{\circ}+\phi^{\prime} / 2\right)$, and $s_{\mathrm{g}}=0.3-2.0$ (average 1.12). High $s_{\mathrm{g}}$ is used to cater for dilatancy, which is less possible for FixH piles.

(4) In a layered soil, the $p_{\mathrm{u}}$ increases by $40 \%$ for a weak layer adjacent to a stiff layer. Conversely, it reduces by $30 \%$ for a stiff layer.

(5) LFP may be directly deduced from p-y curves.

(6) Matching 3 measured responses (e.g. $M_{\max }, w_{\mathrm{g}}$ and moment profile etc), $N_{\mathrm{g}}, \alpha_{\mathrm{o}}$ and $n$ are uniquely deduced using closed-form solutions, which capture overall nonlinear pile-soil interaction rather than soil response only [1]. where $L_{c}$ is a critical pile length beyond which pile response is negligible; and $r_{o}$ is pile radius. (c) $k=\frac{3 \pi G_{s}}{2}\left\{2 \gamma \frac{K_{1}(\gamma)}{K_{o}(\gamma)}-\gamma^{2}\left[\left(\frac{K_{1}(\gamma)}{K_{o}(\gamma)}\right)^{2}-1\right]\right\}$ where $K_{\mathrm{i}}(\gamma)$ is modified Bessel function of second kind of $i^{\text {th }}$ order $(i=0,1)$. The factor $\gamma$ for a sufficiently long fixed-head pile (i.e. $L$ in elastic zone $>L_{\mathrm{c}}$ ) is given by

$$
\gamma=0.65\left(E_{p} / G^{*}\right)^{-0.25}\left(L / r_{o}\right)^{-0.04}
$$

where $\mathrm{G}^{*}=\left(1+3 v_{\mathrm{s}} / 4\right) \mathrm{G}_{\mathrm{s}}$, generally $k=(2.4-$ 3.9) $G_{s}$ with an average of $3 G_{s}$ (clay) and $3.2 G_{s}$ (sand).

(d) $\quad N_{p}=\pi r_{o}^{2} G_{s}\left\lfloor\left(K_{1}(\gamma) / K_{o}(\gamma)\right)^{2}-1\right\rfloor$

These expressions may be readily estimated using a spreadsheet operating in $\mathrm{EXCEL}^{\mathrm{TM}}$ [2] 
These expressions allow the critical slenderness length $L_{\mathrm{c}}$, the modulus of subgrade reaction $k$, and the fictitious tension $N_{\mathrm{p}}$ to be computed. For instance, $L_{\mathrm{c}}$ is calculated as $1.1 d\left[\left(1+0.75 v_{\mathrm{s}}\right)\left(E_{\mathrm{p}} / G_{\mathrm{s}}\right)\right]^{0.25}$, where $E_{\mathrm{p}}$ is Young's modulus of an equivalent solid pile; $G_{\mathrm{s}}$ is an average shear modulus of the soil over the effective length $L_{\mathrm{c}}$; $d$ is pile diameter; and $v_{\mathrm{s}}$ is Poisson's ratio of the soil. Given an embedded length $L>L_{\mathrm{c}}+\max x_{\mathrm{p}}$, the fixed-head pile behaves as if infinitely long. Note that max $x_{\mathrm{p}}$ is the depth of plastic zone under a maximum imposed head load, $P_{\max }$ (see Table II). Most of laterally loaded piles used in practice are found as infinitely long. The expressions given in Table II and developed later on in this paper are generally applicable (otherwise the solutions for a rigid pile should be considered [10-12]).

\subsection{Generic net limiting force profiles (LFP) (Plastic state)}

The net limiting force per unit length, $p_{\mathrm{u}}$ around the laterally loaded pile (see Figure 2) may be described by either of the following expressions [1].

$$
\begin{gathered}
p_{u}=\tilde{s}_{u} N_{g} d\left[\left(x+\alpha_{o}\right) / d\right]^{n} \quad(\text { Cohesive soil) } \\
p_{u}=\gamma_{s}^{\prime} N_{g} d^{2}\left[\left(x+\alpha_{o}\right) / d\right]^{n} \text { (Cohesionless soil) }
\end{gathered}
$$

where $p_{\mathrm{u}}$ is net limiting force per unit length $\left[\mathrm{FL}^{-1}\right] ; x$ is depth below ground level $[\mathrm{L}] ; \alpha_{\mathrm{o}}$ is an equivalent depth to include the $p_{\mathrm{u}}$ at mudline level $[\mathrm{L}] ; n$ is a power showing the increase in the $p_{\mathrm{u}}$ with depth; $\tilde{s}_{u}$ is average undrained shear strength $s_{\mathrm{u}}$ of the soil $\left[\mathrm{FL}^{-2}\right]$ over the max $x_{\mathrm{p}}$ anticipated; $N_{\mathrm{g}}$ is a gradient correlated clay strength or sand density to the limiting $\mathrm{p}_{\mathrm{u}}$, which depends on head constraints; $\gamma_{s}^{\prime}$ is effective unit weight of the overburden soil $\left[\mathrm{FL}^{-3}\right]$ (i.e. dry weight above water table, and buoyant weight below). Equation (1) or (2) is only effective to the $\max x_{\mathrm{p}}$. Magnitudes of the parameters $\alpha_{0}, N_{\mathrm{g}}$, and $n$ are independent of load levels over the entire 
loading regime. For layered soil, the $p_{\mathrm{u}}$ can be constructed by using both Eqs. (1) and (2) in a manner similar to that elaborated previously for free-head piles[1].

Ad hoc guidelines for selecting these parameters are established herein, and referred to as G1-

G5 (see Table III).

Table III Guidelines G1-G5 for selecting input parameters

G1 for $\mathrm{G}_{\mathrm{s}} \quad$ - A value of $(0.5 \sim 2.0) \mathrm{G}_{\mathrm{s}}$ (Cases II and III) may be used for FixH piles with $\mathrm{G}_{\mathrm{s}}$ being determined from Table II
$\mathrm{G}_{\mathrm{s}}$, the $k$ is higher for FreH piles than FixH ones (Cases I, IV) [13,14],
- Diameter effect is well considered by the expression correlating $\mathrm{G}_{\mathrm{s}}$ to $k$ (Table II), otherwise, $5-10$ times
from a given $k$. For large diameter piles, a small maximum $x_{\mathrm{p}}$ is seen in gaining the $\widetilde{s}_{u}[16,17]$
- $\mathrm{G}_{\mathrm{s}}$ for piles in a group may increase by 2-10 times in sand (Case III) or may reduce by $50 \%$ in clay (Case III)

\begin{tabular}{|c|c|c|}
\hline$G 2$ & FixH Single piles & Semi-fix \\
\hline Sand & $K_{\mathrm{p}}^{2}($ Cases I and IV $)$ & \\
\hline \multirow[t]{2}{*}{ Silt or clay } & $\begin{array}{ll}\mathrm{n}=\mathrm{n}_{\mathrm{c}}^{\mathrm{FreH}}=0.5-0.7, \text { independent } & \mathrm{n}=1.7 \mathrm{n}_{\mathrm{c}}^{\mathrm{FreH}} \text { if soil strength reduces (Cases } \\
\text { of head restraints (Cases II, III) } & \text { II, III); Otherwise } \mathrm{n}=\mathrm{n}_{\mathrm{c}}{ }^{\mathrm{FreH}} \text { (Case II). }\end{array}$ & ardless of FreH or \\
\hline & $\begin{array}{l}N_{\mathrm{g}}=0.6-4.8, \alpha_{\mathrm{o}}=0.05-0.02 \mathrm{~m} \text { and considering reduction as described in the } \\
\text { note }\end{array}$ & $y$ \\
\hline $\begin{array}{l}\text { Note } \\
\text { for } \mathrm{n} \text { and } \\
N_{\mathrm{g}}\end{array}$ & \multicolumn{2}{|c|}{$\begin{array}{l}\text { - } \mathrm{n} \text { is independent of head restraints for piles in silt/clay, but reduced for FixH piles in sand. A high } n \text { is used } \\
\text { group (Cases II, III); whereas a low } \mathrm{n} \text { is seen for homogenizing sand among a pile group (Case IV), owing } \mathrm{t} \\
\text { piles and sand dilatancy. } \\
\text { - } N_{\mathrm{g}}, n \text { and } \alpha_{\mathrm{o}} \text { are selected by referring to Table II to cater for non-uniform resistance with depth and justified } \\
\text { layered soil. Over a maximum depth } x_{\mathrm{p}} \text {, a low value } N_{\mathrm{g}} \text { of } 0.25 N_{\mathrm{g}}^{\text {FreH }} \text { as mobilised along a FixH pile (Cases } \\
\text { to } N_{\mathrm{g}}=0.7 N_{\mathrm{g}}^{\text {FixH }}[18] \text { ) towards that for a FreH pile, as the fixed-head restraint degrades. }\end{array}$} \\
\hline for $T_{R}$ & \multicolumn{2}{|c|}{$\begin{array}{l}\text { - A close } \mathrm{T}_{\mathrm{R}} \text { leads to similar predictions, insensitive to the values of } \alpha_{\mathrm{o}}, \mathrm{n} \text { and } N_{\mathrm{g}} \text { (Case IV). } \\
\text { - The result of } T_{R}>P_{\max } \text { indicates a FixH condition (Cases III, IV), whereas } T_{R}<P_{\max } \text { implies a FreH condition } \\
\text { resistance of } T_{R}-P_{\max } \text { is induced for FixH pile owing to restraining rotation. }\end{array}$} \\
\hline & \multicolumn{2}{|c|}{ The maximum $x_{\mathrm{p}}$ for FixH piles are initially be taken as $16 d$ for prototype piles, and $20 d$ for model piles (Cases I } \\
\hline & \multicolumn{2}{|c|}{$\begin{array}{l}\text { The } p_{\mathrm{m}} \text { reduces as number of piles in a group increases, e.g. by } 50 \% \text { with } 9 \sim 16 \text { piles in a group [19]. The } p_{\mathrm{m}} \text { is } \\
\text { pile-head restraints (Cases I, III). }\end{array}$} \\
\hline
\end{tabular}


They are synthesized from preceding study on 70 FreH piles (32 piles in clay, 20 piles in sand, and other piles in layered soil, see Table II), and this study on capped piles ( 7 single piles and 27 pile groups). Capitalised on average soil parameters, the impact of soil no-homogeneity and layered properties can be well simulated by adjusting the factor ' $n$ ', as pile response in general is dominated by plastic response, and the average $k$ has negligible impact on pile non-linear response. This is observed for free-head piles, and will be illustrated later for capped piles. Typical cases are highlighted in Table III, which will be elaborated in later sections. Using Eq. (1) or (2) to construct the LFP, it is noted that

- A high $n(=1.3-2.0)$ is needed to capture the impact of a sharply varying strength with depth, whereas a moderate $\mathrm{n}(=0.5-0.7)$ is deduced against a uniform strength profile. The $N_{\mathrm{g}}, n$ and $\alpha_{\mathrm{o}}$ together are flexible to replicate various $\mathrm{p}_{\mathrm{u}}$ profiles, such as that described by $N_{\mathrm{g}}=9.14-$ 11.94 and $\mathrm{n}=0$ for plane strain case [20] (see Table II [1]).

- Given a set of $\mathrm{n}, \alpha_{\mathrm{o}}$ and $N_{\mathrm{g}}$, the total resistance on the pile in plastic zone $\mathrm{T}_{\mathrm{R}}$ is obtained as

$$
T_{R}=\int_{0}^{\max x_{p}} p_{u} d x=\frac{A_{L}}{1+n}\left[\left(\max x_{p}+\alpha_{o}\right)^{n+1}-\alpha_{o}^{n+1}\right]
$$

where $A_{L}=\widetilde{s}_{u} N_{g} d^{1-n}$ (cohesive soil), $A_{L}=\gamma_{s}^{\prime} N_{g} d^{2-n}$ (cohesionless soil); max $x_{\mathrm{p}}$ is calculated per G4. The difference between the resistance $T_{\mathrm{R}}$ and the load $P_{\max }$ renders head restraints to be detected (G3). The input parameters where possible should be deduced from measured data of a similar project [1].

\subsection{Elastic-plastic solutions}

Response of the pile (see Figure 1) is presented against the depth $x$ and a depth $z\left(=x-x_{\mathrm{p}}\right)$, respectively, in the upper plastic, and the lower elastic zones, to generate compact expressions [1].

- In the plastic zone $\left(x \leq x_{\mathrm{p}}\right)$, based on uncoupled model, the governing equation for the pile is 


$$
E_{p} I_{p} w^{I V}(x)=-p_{u} \quad\left(0 \leq x \leq x_{\mathrm{p}}\right)
$$

where $w^{I V}(x)$ is $4^{\text {th }}$ derivative of $w(x)$ with respect to $x ; w(x)$ is the pile deflection at depth $x$; $I_{\mathrm{p}}$ is moment of inertia of an equivalent solid cylindrical pile.

- In the elastic zone, using the coupled model, the governing equation for the pile is $[2,21]$

$$
E_{p} I_{p} w^{I V}(z)-N_{p} w^{\prime \prime}(z)+k w(z)=0 \quad\left(x_{\mathrm{p}} \leq x \leq L, \text { or } 0 \leq z \leq L-x_{\mathrm{p}}\right)
$$

where $w(\mathrm{z})$ is the pile deflection in elastic zone; $w^{\mathrm{IV}}(\mathrm{z})$ and $w^{\prime \prime}(\mathrm{z})$ are $4^{\text {th }}$ and $2^{\text {nd }}$ derivatives of $w(\mathrm{z})$ with respect to depth z. $N_{\mathrm{p}}$ and $k$ are calculated using the average modulus (see Table II).

Equations (4) and (5) are virtually identical to those for free-head piles [1], as is the methodology for resolving the equations. The solution procedure is not reiterated herein. Compared to FreH piles, the apparent alterations are the use of slope $w_{A}^{\prime}(0)=0$, and the shear force $-Q_{\mathrm{A}}(0)=P(P=$ pile-head load) to enforce the FixH restraint at $x=0$. These conditions allow elastic-plastic solutions for fixed-head piles to be developed in this paper.

- Provided in Table IV are the solutions in form of the response profiles using the normalised depths $\bar{x}(=\lambda x)$ and $\bar{z}\left(=\bar{x}-\bar{x}_{p}\right.$, with $\left.\bar{x}_{p}=\lambda x_{\mathrm{p}}\right)$, respectively for plastic and elastic zones (Note that $\lambda$ is the reciprocal of a characteristic length given by $\lambda=\sqrt[4]{k /\left(4 E_{p} I_{p}\right)}$, which controls the attenuation of pile deflection with depth).

- Furnished in Table $\mathrm{V}$ are the solutions in form of normalised pile-head load $\bar{P}\left(=P \lambda^{n} / A_{L}\right)$, mudline deflection $\bar{w}_{g}\left(=w_{\mathrm{g}} k \lambda^{n} / A_{L}\right)$, and bending moment at depth $x\left(<x_{\mathrm{p}}\right) \bar{M}(\bar{x})\left(=M(x) \lambda^{2+\mathrm{n}} /\right.$ $A_{L}$ ). Schematic profiles of the on-pile force per unit length $p$ (with $p=p_{\mathrm{u}}$ at $x \leq x_{\mathrm{p}}$ ), and the moment $M(x)$ are depicted in Figure 3. 


\subsection{Simplified expressions}

The expressions of $\bar{P}, \bar{w}_{g}$, and $\bar{M}_{\text {max }}$ for the single pile are characterized by the $\mathrm{p}_{\mathrm{u}}$ profile and the $\bar{x}_{p}$. Given the $\lambda$ for the pile-soil system and the $\mathrm{p}_{\mathrm{u}}$ for the limiting force profile, the response is featured by the sole slip depth $x_{\mathrm{p}}$. The on-pile resistance at mudline and the coupled interaction may be ignored by taking $\alpha_{\mathrm{o}} \approx 0$ and $N_{\mathrm{p}} \approx 0$, respectively. The dimensionless expressions thus reduce to the following form (referred to as 'Simplified Eqs').

$$
\begin{gathered}
\bar{P}=\bar{x}_{p}^{n} \frac{\left[n^{2}\left(1+\bar{x}_{p}\right)+n\left(2 \bar{x}_{p}^{2}+5 \bar{x}_{p}+4\right)+2 \bar{x}_{p}^{3}+6 \bar{x}_{p}^{2}+6 \bar{x}_{p}+3\right]}{\left(1+\bar{x}_{p}\right)^{2}(n+3)(n+1)} \\
\bar{w}_{g}=\frac{\bar{x}_{p}^{n}}{3(n+4)(n+3)}\left\{\frac{\bar{x}_{p}^{3}+3\left(\bar{x}_{p}^{2}+\bar{x}_{p}+1\right)}{\left(1+\bar{x}_{p}\right)} n^{2}+\frac{2 \bar{x}_{p}^{5}+11 \bar{x}_{p}^{4}+28 \bar{x}_{p}^{3}+21\left(2 \bar{x}_{p}^{2}+2 \bar{x}_{p}+1\right)}{\left(1+\bar{x}_{p}\right)^{2}} n\right. \\
\left.+\frac{2\left[\bar{x}_{p}^{6}+6 \bar{x}_{p}^{5}+15 \bar{x}_{p}^{4}+24 \bar{x}_{p}^{3}+18\left(2 \bar{x}_{p}^{2}+2 \bar{x}_{p}+1\right)\right]}{\left(1+\bar{x}_{p}\right)^{2}}\right\} \\
-\bar{M}_{\max }=-0.5 \bar{x}_{p}^{n} \frac{\left(\bar{x}_{p}+1\right) n^{2}+\left(2 \bar{x}_{p}^{2}+5 \bar{x}_{p}+5\right) n+2\left(\bar{x}_{p}^{3}+3 \bar{x}_{p}^{2}+3 \bar{x}_{p}+3\right)}{\left(\bar{x}_{p}+1\right)(n+3)(n+2)}
\end{gathered}
$$

Note that the $M_{\max }$ is equal to the moment at mudline $M_{o}$ for a FixH pile (see Figure 3). The eccentricity $e$ (Figure 2) vanishs from the expressions of $\bar{P}, \bar{w}_{g}$, and $\bar{M}_{\max }$. Its effect on semifixed head pile may become apparent, which has to be dealt with via a treatment $\mathrm{H} 2$ shown later. These solutions have similar features to FreH solutions [1, 2] (see Tables I and II), except for the differences in the magnitudes of the input parameters. They can be directly used to predict nonlinear response of piles and pile groups. 


\section{Nonlinear Response of Single Piles and Pile Groups}

A pragmatic approach for estimating response of pile groups is depicted herein in terms of the benchmark solutions for a single pile. The pile-pile interaction is considered via incorporating the p-multipliers $p_{\mathrm{m}}$ (or the $p_{\mathrm{m}}$ for individual pile, which is later referred to as $R$ ).

\subsection{Single piles}

The current solutions outlined in Tables IV and V allow nonlinear response of a pile to be predicted. Their numeric values are evaluated in this study using a spreadsheet program called GASLGROUP, which is supported by a purpose- designed macro operating in EXCEL ${ }^{\mathrm{TM}}$. The calculation flow chart is depicted in Figure 4. Starting with a mudline deflection $w_{\mathrm{g}}$ (thus $\bar{w}_{g}$ ), it is epitomized as the following 3 steps:

(1) A slip depth $x_{\mathrm{p}}$ is iteratively obtained using the $\bar{w}_{g}$ expression (see Table V) or Equation (7).

(2) The obtained $x_{\mathrm{p}}$ is utilised to evaluate the responses (e.g. using Equation (6) for the load $P$ ).

(3) The $x_{\mathrm{p}}$ is employed to calculate the profiles of deflection, rotation, bending moment and shear force (see Table IV) for elastic and plastic zones, respectively.

The GASLGROUP differs from the spreadsheet GASLFP [1] in that the latter starts a calculation with a desired load or $x_{\mathrm{p}}$. The two programs, however, do bring about identical results. The current solutions were generally computed using GASLGROUP, except where specified. They, however, may be referred to as ' $\mathrm{CF}(\mathrm{FixH})$ ', ' $\mathrm{CF}(\mathrm{FreH})$ ' for $\mathrm{FixH}$ and $\mathrm{FreH}$ piles, and as 'current $\mathrm{CF}$ ' for either head restraint. 


\subsection{Group piles}

Among a laterally loaded pile group, soil resistance along piles in a trailing row (see Figure 2(b)) is reduced owing to the presence and actions of the piles ahead of the row. This shadowing effect is catered for by using $p$-multiplier method suggested by Brown et al [8], in which the gradient $k$ of a $p-y$ curve for a single pile is multiplied by a $p$-multiplier, $p_{\mathrm{m}}(\leq 1)$, so is the limiting force per unit length, $p_{\mathrm{u}}$. This generates a squashed $p-y$ curve (dashed line in Figure 2(e)) for piles in the same row. In particular, the shape of LFP ( $p_{u}$ profile) is also allowed to be altered via a new 'n' (G1-2, Table III).

The $p_{m}$ may be estimated using Equation (9) as is plotted in Figure 5(a).

$$
p_{m}=1-a(12-s / d)^{b}
$$

where $\mathrm{s}$ is pile center-to-center spacing; $a=0.02+0.25 \operatorname{Ln}(\mathrm{m}) ; b=0.97(\mathrm{~m})^{-0.82}, \mathrm{~m}=$ row number. For instance, given the second row with $\mathrm{m}=2$, it follows that $a=0.193$, and $b=0.55$. The row number $\mathrm{m}$ should be taken as 3 , for $3^{\text {rd }}$ and subsequent rows. The $p_{m}$ varies with row position, the spacing, configuration of piles in a group, and pile installation method. Values of the $p_{\mathrm{m}}$ for 24 pile groups were deduced by gaining most favourable predictions against measured data in a manner described later on. They are provided in Table VI and plotted in Figure 5(a) and (b). Insights about the $p_{\mathrm{m}}$ as gleaned herein are provided in Table III. The $p$-multipliers exceed those suggested by other investigators at large spacing [22, 23], but compare well with recent suggestions [24]. This is also because the calculated $p_{\mathrm{m}}$ using Equation (9) should be reduced as number of piles in a group increases (see Figure 5(b)). Furthermore, the $p_{\mathrm{m}}$ varies from one pile to another (i.e. $R$ ) in a row to characterise response of individual piles.

Based on the single pile solutions, pile groups (see Figure 4) are analysed via the following steps. 
(1) Values of $p_{\mathrm{m}}$ (or $R$ ) and $n$ are assigned, this generates a new gradient of $p_{\mathrm{u}} p_{\mathrm{m}}\left(\right.$ or $R p_{\mathrm{u}}$ ), and a new LFP for the pile, as schematically depicted in Figure 2(c).

(2) Substituting the new LFP and $p_{\mathrm{m}} G_{\mathrm{s}}\left(R G_{\mathrm{s}}\right)$ for the LFP and $\mathrm{G}_{\mathrm{s}}$ in the fixed-head solutions, response of the pile (e.g. load $P$ ) is calculated (see Figure $4(\mathrm{~b})$ ) as if it were a single isolated pile and for a specified mudline deflection $w_{\mathrm{g}}$ [the $w_{\mathrm{g}}$ is assumed identical for any piles in the group unless specified].

(3) Steps (1)-(2) are repeated for other rows using the $p_{\mathrm{m}}$ obtained from Eq. (9) (or other piles in the same row using the $R$ ). The $P$ offers the total load $P_{\mathrm{g}}$ on the group for the prescribed $w_{\mathrm{g}}$.

Steps (1)-(3) are repeated for a series of desired $w_{\mathrm{g}}$, which allow load-deflection curves of each pile $\left(P-w_{\mathrm{g}}\right)$, each row, and the group $\left(P_{\mathrm{g}}-w_{\mathrm{g}}\right)$ to be generated. Likewise, other responses are evaluated such as the moment by using $\bar{M}_{\max }$. This calculation is incorporated into GASLGROUP. Unlike the provisos specified, the head-load may be exerted at a free length $e_{p}$ and deflection $w_{\mathrm{t}}$ be measured at a free length $e_{w}$ above mudline on a free-standing pile-cap. A FixH restraint for each capped pile in a group is not warranted particularly at a large deflection (thus referred to as semiFixH pile), as noted in a majority of tested groups [7] (observation H1). To contend with these complications, the current solutions should be used together with an approximate treatment $\boldsymbol{H} 2$. The $\mathbf{H} 2$ is proposed, however, to cater to only two typical (Types (A) and (B)) head restraints, as elaborated in Figure 6. It is given as Treatments $\mathrm{H} 2 \mathrm{a}, \mathrm{H} 2 \mathrm{~b}$ and $\mathrm{H} 2 \mathrm{c}$, respectively for assessing $M_{0}$ [25], moment profile for $\boldsymbol{e}_{\boldsymbol{p}} \neq 0$, and the difference between the $w_{\mathrm{t}}$ and $w_{\mathrm{g}}[26,27]$.

\section{Validation}

The newly established closed-form (CF) solutions can be reduced to these for elastic state (e.g. Table IV) that were validated previously [2]. Equivalent solutions for FreH piles have been proved 
to be sufficiently accurate. Thereby, verification is only sought for the impact of the FixH feature, and from the following three perspectives. It is presented in Cases I-IV in subsequent sections.

- The accuracy of the new solutions is dominated by the LFP [1], despite the use of five presumptions outlined in Table II. The $p-y$ curve based program COM624P directly utilises a specified LFP. Given a similar LFP, the solutions and the COM624P offer very similar predictions [17] (Case IV).

- GASLGROUP predictions are compared with FEM analysis and measured data [28] regarding single and group piles (Cases I, and II), to complement the previous corroborations using full scale and model tests $[8,27,29-31]$, and to verify the treatment $\mathrm{H} 2$.

- The simplified Equations (6)-(8) are used to check the algebra for the typical Cases I IV. The difference between the prediction using GASLGROUP and the simple expressions allow the impact of the $N_{\mathrm{p}} \neq 0$ (given $\alpha_{0}=0$, Cases I, II, and IV) to be assessed.

Cases I and II are presented in this section and focused on validation, whereas Cases III and IV are aimed at showing comparisons with measured data.

\subsection{Case I: $\quad$ Model tests on piles in sand [28]}

Model tests on two single piles were performed in a tank of $2.5 \mathrm{~m} \times 2.0 \mathrm{~m} \times 1.7 \mathrm{~m}$ (height), under FreH and capped-head restraints, respectively. Each aluminium pipe pile was $1.45 \mathrm{~m}$ in length $(L), 50 \mathrm{~mm}$ in outside diameter $\left(d_{\mathrm{o}}\right)$, and $1.5 \mathrm{~mm}$ in wall thickness $(\mathrm{t})$. It had a flexural stiffness $E_{\mathrm{p}} I_{\mathrm{p}}$ of $4.612 \mathrm{kNm}^{2}$. The piles were installed into a dense sand that had an angle of friction $\phi$ of $42^{\circ}$, unit weight $\gamma_{\mathrm{s}}$ of $15.3 \mathrm{kN} / \mathrm{m}^{3}$, and Poisson's ratio $v_{\mathrm{s}}$ of 0.4 . The soil and pile properties are summarised in Tables VI and VII. Lateral load $(P)$ was imposed at $50 \mathrm{~mm}$ above mudline (i.e. $\boldsymbol{e}_{\boldsymbol{p}}=50 \mathrm{~mm}$ ), and deflection $\left(w_{t}\right)$ was measured at the same level (i.e. $\boldsymbol{e}_{w}=\boldsymbol{e}_{\boldsymbol{p}}$ ). These 
measured $P-w_{\mathrm{t}}$ relationships for the piles are plotted in Figure 7(a), along with the 3 dimensional FEM predictions [28]. Measured and $\mathrm{FEM}^{3 \mathrm{D}}$ predicted moment profiles are plotted in Figure 7(b) for $w_{\mathrm{t}}=w_{\mathrm{g}}=0.5,2.0$ and $5.0 \mathrm{~mm}$.

The same piles as mentioned above were installed at a center-to-center spacing, $\mathrm{s}$ of 2.5 pile diameters. Model tests were conducted on two $3 \times 3$ pile groups [28] in the tank. Deflections (at an $\boldsymbol{e}_{w}=50 \mathrm{~mm}$ ) under the total loads of $P_{\mathrm{g}}$ exerted on the group (with $\boldsymbol{e}_{\boldsymbol{p}}=\boldsymbol{e}_{w}$ see Figure 6) were measured. The average lateral load per pile $P_{\mathrm{av}}\left(P_{\mathrm{av}}=P_{\mathrm{g}}\right.$ /number of piles in the group $)$ is plotted against the measured $w_{\mathrm{t}}$ in Figure 8 for both free-head and fixed-head (capped) groups, along with the $\mathrm{FEM}^{3 \mathrm{D}}$ predictions [28]. The measured moments for leading and back rows are given in Table VIII for $w_{\mathrm{g}}=5 \mathrm{~mm}$.

Responses of the two single pile and the two pile groups were predicted using the current solutions (i.e. GASLGROUP and Equations (6)-(8)), in light of the parameters that follows: $\mathrm{G}_{\mathrm{s}}=$ 2.35 MPa, $n=1.15$ (or $\mathrm{n}=0.575$ for the FixH group, G2), $N_{\mathrm{g}}=25.45\left(=K_{\mathrm{p}}^{2}\right.$ ), and $\alpha_{\mathrm{o}}=0 \mathrm{~m}$. The $\mathrm{G}_{\mathrm{s}}$ was deduced from the Young's modulus $\mathrm{E}_{\mathrm{s}}$ of $19.6\left[\gamma_{\mathrm{s}} x\right]^{0.5}[28]$, in which $x=0.725 \mathrm{~m}$, middle depth of the pile penetration, and $v_{\mathrm{s}}=0.4$. Values of the $\mathrm{n}$ and $N_{\mathrm{g}}\left(s_{\mathrm{g}}=1\right)$ were selected according to $\mathbf{G 2}$. The impact of the cap fixity condition on the LFP was neglected as justified subsequently.

\section{(a) Single Piles}

The $P-w_{\mathrm{g}}$ responses predicted for the FreH pile [1] and the capped pile are depicted in Figure 7(a). They all well replicate the $\mathrm{FEM}^{3 \mathrm{D}}$ analysis and the measured $P-w_{\mathrm{t}}$ curves (implying $w_{\mathrm{t}}$ $\approx w_{\mathrm{g}}$ for the FixH pile). In particular, ignoring the impact of the membrane by taking $N_{\mathrm{p}}=0$, Equations (6-8) slightly overestimated the head stiffness (load over displacement) of the FixH pile, as is noted later in other cases. Use an identical $\mathrm{G}_{s}$ of $2.35 \mathrm{MPa}$, the $k$ of $1.50 \mathrm{MPa}$ [2] 
obtained for the FreH pile exceeds that for the FixH pile by $18.2 \%$, a phenomenon noted previously [14].

GASLGROUP offers bending moment profiles along the capped pile, which are compatible with the $\mathrm{FEM}^{\mathrm{BD}}$ predictions (see Figure 7(b)). Both predictions, however, overestimate the measured moment $M_{\mathrm{o}}$ at mudline, implying a semi-FixH group, as is confirmed by the following.

- A similar capped group in the same test program did rotate 1.3 degrees (rotation angle $\theta_{w}$ at the $\mathrm{e}_{\mathrm{w}}$ level) at a pile-cap deflection $w_{\mathrm{t}}$ of $20 \mathrm{~mm}$. The $w_{\mathrm{g}}$ may virtually be $4 \mathrm{~mm}$, for instance, at $w_{\mathrm{t}}=5 \mathrm{~mm}$, considering $\theta_{w}=1.1^{\circ}$ at $\mathrm{e}_{\mathrm{w}}=50 \mathrm{~mm}$.

- The predicted moment profiles once plotted against the revised depth of $x-\mathrm{e}_{\mathrm{p}}\left(\mathrm{e}_{\mathrm{p}}=50 \mathrm{~mm}\right)$ (H2) match well with the measured profiles (not shown herein).

- The total resistance $T_{R}$ at the maximum $w_{\mathrm{g}}=20 \mathrm{~mm}$ was $2.153 \mathrm{kN}[=15.3 \times$ $25.45 \times 0.05^{0.85} \times(0.416)^{2.15} / 2.15$, as per Equation (3)], which is less than $P(=3.4 \mathrm{kN})(\mathbf{G} 4)$. At the load, the maximum $x_{\mathrm{p}}$ was $8.32 \mathrm{~d}$.

(b) Group Piles

The responses of the two groups were predicted using $p_{m}=0.8,0.4$, and 0.3 (regardless of head constraints, G5) for the leading (LR), middle (MR), and trailing rows (TR) [8], and the aforementioned values of $\mathrm{G}_{\mathrm{s}}, N_{\mathrm{g}}, \alpha_{\mathrm{o}}$, and $\mathrm{n}$ (see Table VI), except for $\mathrm{n}$ being reduced to 0.58 (FixH, G2). Typical load $P_{\mathrm{av}}$ and moment $M_{\max }$ predicted are tabulated in Table VIII for $w_{\mathrm{g}}=5$ $\mathrm{mm}$.

The predicted load $\left(P_{\mathrm{av}}\right)$-deflection $\left(w_{\mathrm{g}}\right)$ curves are in good agreement with the measured $P_{\mathrm{av}}-w_{\mathrm{t}}$ relationships, and the $\mathrm{FEM}^{3 \mathrm{D}}$ predictions [28] (see Figure 8) for either group. The capped 
group has a semi-fixed head. Incorporating the cap effect allows the maximum moment $M_{\mathrm{o}}$ (= $M_{\max }+P_{a \nu} \mathrm{e}_{\mathrm{p}}$ ) to be estimated as $0.25-0.292 \mathrm{kNm}$ for the leading row piles, which slightly exceeds $0.239 \mathrm{kNm}$ obtained from the $\mathrm{FEM}^{3 \mathrm{D}}$ study (Table VIII); whereas the $M_{\mathrm{o}}$ of $0.158-0.182 \mathrm{kNm}$ obtained for the trailing row piles is close to the $\mathrm{FEM}^{3 \mathrm{D}}$ prediction of $0.182 \mathrm{kNm}$. Both predictions nevertheless exceed the respectively measured moments of $0.148 \mathrm{kNm}$ and 0.115 $\mathrm{kNm}$, pinpointing again the effect of $w_{\mathrm{t}}-w_{\mathrm{g}}$. In the capped group, at $w_{\mathrm{g}}=20 \mathrm{~mm}, x_{\mathrm{p}}$ was gained as 8.5d, 6.1d and 6.2d, for piles in LR, MR and TR respectively under a load $\left(P_{\text {av }}\right)$ of $0.99 \mathrm{kN}, 0.64$ $\mathrm{kN}$ and $0.53 \mathrm{kN}$. Values of the $x_{\mathrm{p}}$ are slightly less than $8.6 \mathrm{~d}$ obtained for the single pile at the same $w_{\mathrm{g}}$.

Overall, the semi-FixH restraint reduces the moment, and increases the value $w_{\mathrm{t}}-w_{\mathrm{g}}$. The current solutions for FixH piles are accord with the continuum based $\mathrm{FEM}^{3 \mathrm{D}}$ analysis [28].

\subsection{Case II: In-situ tests on piles in 'silty sand' [28] - (Cap effect)}

A steel pipe pile was tested in-situ [28] under FreH conditions. The pile had dimensions of $L=14.5 \mathrm{~m}, d_{\mathrm{o}}=0.319 \mathrm{~m}$, and $t=6.9 \mathrm{~mm}$, and flexural stiffness of $E_{\mathrm{p}} I_{\mathrm{p}}=5.623 \mathrm{MNm}^{2}$. Effective soil properties to a depth of $2.7 \mathrm{~m}$ are as follows: $\mathrm{c}^{\prime}($ cohesion $)=0-16.7 \mathrm{kPa}, \phi^{\prime}=34.4^{\circ}$, and $\gamma_{s}^{\prime}=$ $12.7 \mathrm{kN} / \mathrm{m}^{3}$. The classification of subsoil, not reported, is herein referred to as 'silty sand'. Load $P$ was applied, and deflection $w_{\mathrm{t}}$ was measured at the same eccentricity $\left(\boldsymbol{e}_{\boldsymbol{p}}=\boldsymbol{e}_{\boldsymbol{w}}\right)$ of $0.5 \mathrm{~m}$ on the single pile. Nine of the pipe piles were installed at the site and at a spacing $s=2.5 d_{0}$. Designed to have a FixH restraint (see Figure 6), the load $P_{\mathrm{g}}$ was applied on the group at $\boldsymbol{e}_{\boldsymbol{p}}=1.3 \mathrm{~m}$, and deflection $w_{\mathrm{t}}$ measured at $\boldsymbol{e}_{w}=0.3 \mathrm{~m}$. Measured curves of $P-w_{\mathrm{t}}$ (single pile), and $P_{\mathrm{g}}-w_{\mathrm{t}}$ (the pile group) are shown in Figure 9(a), and (b), respectively. Bending moments $M_{\mathrm{o}}$ for the piles in 
leading and trailing rows were measured and are provided in Table IX for two load levels. They were predicted using the FixH solutions, and for the single pile using the FreH solutions.

\section{(a) Single Piles}

The $P$ - $w_{\mathrm{g}}$ curve was predicted, assuming FixH condition, using $\mathrm{G}_{\mathrm{s}}=10.2 \mathrm{MPa}, n=0.5, \alpha_{\mathrm{o}}$ $=0 \mathrm{~m}$, and $N_{\mathrm{g}}^{\mathrm{FixH}}=31.3\left[=2.4 K_{\mathrm{p}}^{2}\right](\mathbf{G} 2)$. The $\mathrm{G}_{\mathrm{s}}$ is 1.8 times its initial value and the $N_{\mathrm{g}}$ increases by 2.4 times $\left(s_{\mathrm{g}}=2.4\right)$, owing to pile driving action [28]. The $P$ - $w_{\mathrm{g}}$ curve was also predicted in light of the FreH solutions [28] by employing $\mathrm{G}_{\mathrm{s}}$ and $N_{\mathrm{g}}^{\mathrm{FreH}}$ that were 4 times these used for FixH piles as per $\boldsymbol{G} \mathbf{1}$, i.e. $\mathrm{G}_{\mathrm{s}}=48.9 \mathrm{MPa}$ and $N_{\mathrm{g}}^{\mathrm{FreH}}=125.17$.

The three predictions closely trace the measured $P-w_{\mathrm{t}}$ data [see Figure 9(a)]. Again use of $N_{\mathrm{p}}=0$ renders the pile-head stiffness to be overestimated. The low $n$ vindicates a typical feature of piles in clay [1]. The rotation restraint may render the increase in the $N_{\mathrm{g}}$ and $\mathrm{G}_{\mathrm{s}}$ to be slightly less than 4 times, as implied by the stiffer response of the FreH case [see Figure 9(a)] than the fixedhead case. The $x_{\mathrm{p}}(\mathrm{FixH})$ was gained as $7.6 \mathrm{~d}\left(w_{\mathrm{g}}=100 \mathrm{~mm}\right)$, and $10 \mathrm{~d}\left(w_{\mathrm{g}}=200 \mathrm{~mm}\right)$.

\section{(b) Group Piles}

In the prediction of the group response, the $p_{m}$ specified in Table VI, $\alpha_{\mathrm{o}}=0 \mathrm{~m}$ and $N_{\mathrm{g}}^{\mathrm{FixH}}=$ 31.3 were utilised, along with either

(1) $n=1.2$ and $\mathrm{G}_{\mathrm{s}}=10.2 \mathrm{MPa}$ [i.e. treating the soil as 'sand' (G2)]; or

(2) $n=0.85$ and $\mathrm{G}_{\mathrm{s}}=20.44 \mathrm{MPa}$ (= twice that for the single pile) (G1) (treating as clay).

The two predicted total load $\left(P_{\mathrm{g}}\right)$-deflection $\left(w_{\mathrm{g}}\right)$ curves follow closely with the measured $P_{\mathrm{g}}$ versus $w_{\mathrm{t}}$ relationship, as evident in Figure 9(b). The dashed line from the 'clay' prediction is again more close to the measured one. The pile-cap is close to fixed head. The predicted load $P_{a v}$ and moment $\mathrm{M}_{\max }$ for the 'clay analysis' are provided in Table IX for the two typical load $\left(P_{\mathrm{g}}\right)$ levels of $392 \mathrm{kN}$ and $1570 \mathrm{kN}$. The thick pile-cap generates a moment of $1.3 P_{a v} \mathrm{kNm}\left(P_{a v}\right.$ in $\left.\mathrm{kN}\right)$, 
thereby $M_{\mathrm{o}}=M_{\max }+1.3 P_{a v}$. The $M_{\mathrm{o}}$ obtained for each row at the two load levels is $\sim 18.3 \%$ less than the measured values, indicating the validity of the $\mathrm{H}_{2}$ treatment (Type B). The slip depths at $w_{\mathrm{g}}=$ $200 \mathrm{~mm}$ were deduced as $9.06 \mathrm{~d}(\mathrm{LR}), 10.2 \mathrm{~d}(\mathrm{MR})$ and $10.7 \mathrm{~d}(\mathrm{TR})$, respectively using the 'clay' analysis, which are $\sim 45 \%$ more than $6.6 \mathrm{~d}, 7.2 \mathrm{~d}$ and $7.4 \mathrm{~d}$ obtained from the 'sand' analysis (compared to $41 \%$ increase in the $\mathrm{n}$ values from 0.85 to 1.2 ). They are slightly higher (clay) or less (sand) than 10d obtained for the single pile.

\section{Comparison with Experimental Results}

The current solutions were utilised to study Case III regarding in-situ tests on 1 single pile and 2 pile groups in clay, and Case IV addressing 2 single piles and 19 model pile groups in sand.

\subsection{Case III: In-situ full scale tests on piles in clay [25]}

Matlock et al [25] performed lateral loading tests on a single pile, two circular groups with 5-pile and 10-pile, respectively (see Figure 10a). The tubular steel piles had dimensions of $L=$ $13.4 \mathrm{~m}, d_{\mathrm{o}}=168 \mathrm{~mm}$, and $t=7.1 \mathrm{~mm}$, and stiffness of $E_{\mathrm{p}} I_{\mathrm{p}}=2.326 \mathrm{MN}-\mathrm{m}^{2}$. They were driven $11.6 \mathrm{~m}$ into a uniform soft clay that had a $\mathrm{s}_{\mathrm{u}}$ of $20 \mathrm{kPa}$. The center-to-center spacing between adjacent piles was 3.4 pile diameters in the 5-pile group, and 1.8 pile diameters in the 10-pile group. Deflections of the pile and each group during the tests were enforced at two support levels with $\boldsymbol{e}_{\mathbf{p}}=0.305$ and $1.83 \mathrm{~m}$ above mudline to simulate FixH restraints (see Figure 6). Measured relationships of $P-w_{\mathrm{t}}\left(\right.$ with $\left.\boldsymbol{e}_{\mathbf{w}}=0.305 \mathrm{~m}\right)$, and $w_{\mathrm{t}}-M_{\max }\left(\right.$ with $\left.\boldsymbol{e}_{\mathbf{m}}=0.305 \mathrm{~m}\right)$ are plotted in Figure 11(a) and (b), respectively for the single pile. Measured $P_{\mathrm{av}}-w_{\mathrm{t}}$ and $w_{\mathrm{t}}-M_{\max }$ curves for a pile in the 5-pile and the 10-pile groups are plotted in Figure 11(c) and (d). These measured responses were simulated using the current solutions, in light of the parameters given in Table X. 


\section{(a) Single Piles}

In predicting the single pile, Table $\mathrm{X}$ indicates $\mathrm{G}_{\mathrm{s}}=100 \mathrm{~s}_{\mathrm{u}}$, and $N_{\mathrm{g}}^{\mathrm{FreH}}=4.0$ using the FreH solutions [1]; whereas $\mathrm{G}_{\mathrm{s}}=50 \mathrm{~s}_{\mathrm{u}}$, and $N_{\mathrm{g}}^{\mathrm{FixH}}=1.0$ using the FixH solutions (G1 and G2). Both predictions adopt $n=0.55$, and $\alpha_{\mathrm{o}}=0.05 \mathrm{~m}(\mathbf{G} 2)$. The low values, especially $N_{\mathrm{g}}$, for the FixH case, reflect a reduction in limiting force per unit length caused by the restraint on rotation. The LFPs were accordingly plotted in Figure 10(b) as 'FreH' and 'FixH' to the maximum slip depths determined subsequently.

The three predicted $P-w_{\mathrm{g}}$ curves, as plotted in Figure 11(a) show little discrepancy from the measured $P-w_{\mathrm{t}}$ data. Overestimation of FixH pile-head stiffness using $N_{\mathrm{p}}=0$ in this case is likely offset by reduction in the stiffness using $\alpha_{\mathrm{o}}=0$ (the actual $\alpha_{\mathrm{o}} \neq 0$ ), and $w_{\mathrm{t}} \approx w_{\mathrm{g}}$. The pile-head must be semi-fixed as outlined in the following:

(1) The computed $M_{\max }$ using the FixH solutions was reduced by $0.305 P \mathrm{kNm}\left(P\right.$ in $\mathrm{kN}$, and $\mathbf{e}_{\mathbf{p}}=$ $0.305 \mathrm{~m})$ to cater to the impact of the upper level loading [Type (A), H2b]. The three predicted $w_{\mathrm{g}}-M_{\max }$ curves (either head conditions), as plotted in Figure 11(b) are also consistent with the measured $w_{\mathrm{t}}-M_{\max }$ relationship.

(2) Limited by the ratio $p_{u} /\left(s_{u} d\right)$ of 9.14-11.94 [1] [20], see Figure 10(b), the pile must be semiFixH once $x_{p} / \mathrm{d}>4$, to induce a LFP similar to that of 'Bogard \& Matlock'.

(3) Under the load $P_{\max }$ of $32.4 \mathrm{kN}$, limiting force is fully mobilised to a depth $x_{\mathrm{p}}$ of $8 \mathrm{~d}$ (FreH) to 15.1d (FixH) (see Table X, and G4). The total resistances $T_{R}{ }^{\text {FixH }}$ and $T_{R}{ }^{\text {FreH }}$ were $36.35 \mathrm{kN}$ and $24.42 \mathrm{kN}$, respectively (i.e. $T_{R}^{\text {FreH }}<P_{\max }<T_{R}^{\text {FixH }}$, G3). An additional $4 \mathrm{kN}(=36.35-32.4)$ resistance was mobilised to restrain the head rotation. 
(b) Group Piles

In analysing the two pile groups, identical $n$ and $\mathrm{p}_{\mathrm{m}}$ were adopted using either solutions (see Table $\mathrm{X}$ ). The $\mathrm{n}$ is $70 \%$ higher than that for the single pile, reflecting group disturbance (G2 and G5). Shear modulus $\mathrm{G}_{\mathrm{s}}$ was taken as $17 \mathrm{~s}_{\mathrm{u}}(\mathrm{FixH})$ or $33 \mathrm{~s}_{\mathrm{u}}(\mathrm{FreH})$ for the 10-pile group. It is very low and not proportional to the adopted $p_{\mathrm{m}}$ of 0.333 and 0.2 [25] (G5), implying the impact of the unusually small spacing of $1.8 \mathrm{~d}$ G1) and the special pile layout. The $\mathrm{G}_{\mathrm{s}}$ was calculated as $75 s_{\mathrm{u}}(\mathrm{FixH})$, or $100 \mathrm{~s}_{\mathrm{u}}($ FreH) for the 5-pile group at a normal $\mathrm{s}=3.4 \mathrm{~d}$.

The average load per pile $\left(P_{\mathrm{av}}\right)$ - mudline deflections $\left(w_{\mathrm{g}}\right)$ predicted are presented in Figure 11(c). They agree remarkably well with the respectively measured $P_{\mathrm{av}}-w_{\mathrm{t}}$ curves (thus $w_{\mathrm{t}} \approx w_{\mathrm{g}}$ ). The group behaves as semi-fixed head one. The LFPs were obtained for each group, and are plotted in Figure 10(c) and (d), respectively. They show similar features to those of the single pile. The predicted $M_{\max }$ [after deducting the amount of $P_{a v} e_{p}(\mathrm{H} 2 \mathrm{a})$ for the FixH groups] are plotted in Figures 11(d) and 12(b). They still exceeds the measured values, indicating a higher reduction than $P_{a v} e_{p}$ in response to the increased number of piles and loading levels, and the need to incorporate value of $w_{\mathrm{t}}-w_{\mathrm{g}}(\mathrm{H} 2 \mathrm{c})$. The max $x_{\mathrm{p}}$ along each pile increases by $18 \%$ (from $19.6 \mathrm{~d}$ to 23.2d) from the 5-pile to the 10-pile groups, even if the load $P_{\mathrm{av}}$ reduces by $9 \%$ (from 27.3 to 24.8 $\mathrm{kN})$.

\subsection{Case IV: Model tests on piles in sand [32] - small values of $e_{w}=e_{p}$}

Two single piles and nineteen pile groups were tested in the laboratory [32]. The aluminium pipe piles were driven into a depth of $0.5 \mathrm{~m}$, with $L=0.75 \mathrm{~m}, d_{\mathrm{o}}=18.2 \mathrm{~mm}, t=0.75$ $\mathrm{mm}$, and $E_{\mathrm{p}} I_{\mathrm{p}}=0.086 \mathrm{kN}-\mathrm{m}^{2}$. The fine to medium sand was clean and dry with properties of: $D_{\mathrm{r}}$ (a relative density) $=60 \%, \phi=36.3^{\circ}, \gamma_{\mathrm{s}}=14.6-17.3 \mathrm{kN} / \mathrm{m}^{3}, v_{\mathrm{s}}=0.25$. One capped, single pile was 
tested with $\mathbf{e}_{\mathbf{p}}=\mathbf{e}_{\mathbf{w}}=0.047 \mathrm{~m}$. The head was constrained by a wooden plank reinforced with a mild steel strip. Another single pile was tested under FreH restraint. The groups had a spacing, $\mathrm{s}$ of (4-12) $\mathrm{d}_{\mathrm{o}}$ in the loading direction, and a constant $\mathrm{s}\left(=3 \mathrm{~d}_{\mathrm{o}}\right)$ within each row. They were tested with $e_{\mathrm{p}}=35 \mathrm{~mm}$, and $e_{\mathrm{w}} \approx 85 \mathrm{~mm}$ (measured from the test set-up).

The following measured responses are plotted herein: (1) The $P-w_{\mathrm{t}}$ relationships for the single FreH and capped piles in Figure 13(b). (2) The two values of the $M_{\max }$ in Figure 13(c). (3) The moment profiles at $w_{\mathrm{t}}=10 \mathrm{~mm}$ for the two single piles in Figure 14(c). (4) The $w_{\mathrm{t}}-P_{\mathrm{g}}$ relationships for the 2-row (see Figure 15) and the 3-row (see Figure 16) groups. Responses of the two single piles were well predicted previously using the current solutions compared to measured data [6], in light of GASLGROUP and the parameters tabulated in Tables XI and XII. Further study using the current solutions on the piles and the pile groups was conducted herein.

\section{(a) Single Piles}

Sensitivity of the current solutions to the input parameters was examined by selecting (see Table XII) $\alpha_{\mathrm{o}}=0 \mathrm{~m}$, and $n=1.7$ for either pile, along with $N_{\mathrm{g}}^{\mathrm{FixH}}=6.86\left[=0.45 K_{\mathrm{p}}^{2}\right]$, or $N_{\mathrm{g}}^{\text {FreH }}=$ $30.45\left[=2 K_{\mathrm{p}}^{2}\right]$. These offer LFPs of $\mathrm{CF}(\mathrm{FixH})$ and $\mathrm{CF}(\mathrm{FreH})$ in Figure 13(a). The $P$ - $w_{\mathrm{g}}$ curves predicted for FixH and FreH [1] conditions are plotted with the measured data in Figure 13(b). They well mirror the measured $\mathrm{P} \sim w_{\mathrm{t}}$ relationship for either pile. The impact of $N_{\mathrm{p}} \neq 0$ is seen for the fixed-head case in the figure. The subgrade reaction $k$ increase by $17 \%$ from $711.71 \mathrm{kPa}$ (FixH) to $831.1 \mathrm{kPa}\left(\right.$ FreH) [2] (see Table XI), given the $\mathrm{G}_{\mathrm{s}}(=0.3 \mathrm{MPa})$ deduced from similar tests in sand [16]. The predicted $M_{\max }$ is plotted Figure 13(c); the response profiles predicted for $w_{\mathrm{g}}=10 \mathrm{~mm}$ are plotted in Figure 14, together in particular, with those predicted for the capped pile using COM624P. The $M_{\max }$ predicted for the FreH pile slightly exceeds the only measured 
point. The bending moment profile of $\mathrm{CF}(\mathrm{FreH})$ agrees with the measured one. The capped pile has a semi-fixed head as outlined in the following.

- The $M_{\mathrm{o}}$ at mudline level (solid line) for the capped pile compares well with the other measured point ' $\times$ ', with $M_{\mathrm{o}}=M_{\max }($ FixH $)-P \cdot \mathrm{e}_{\mathrm{p}}\left(\mathrm{e}_{\mathrm{p}}=0.047 \mathrm{~m}, \boldsymbol{H} 2 \boldsymbol{a}\right.$, Figure 6). Without the deduction, the $\mathrm{CF}(\mathrm{FixH})$ would match well with the COM624P(FixH) (not shown herein).

- Under a $30 \%$ higher $P_{\max }(=0.332 \mathrm{kN})$, the slip depth reduces by $50 \%$ from $12.55 \mathrm{~d}$ (i.e $x_{\mathrm{p}}{ }^{\text {FixH }}$ ) to $6.47 \mathrm{~d}\left(x_{\mathrm{p}}^{\mathrm{FreH}}\right.$ under the $P_{\max }$ of $\left.0.255 \mathrm{kN}\right)(\mathbf{G} 4)$. The estimated $T_{\mathrm{R}}{ }^{\text {FreH }}$ (see Table XII) varies $3.6 \%$ between $0.165 \mathrm{kN}$ (previous study) and $0.171 \mathrm{kN}$ (current study). Both are less than $P_{\max }(=0.255 \mathrm{kN})$. The $T_{\mathrm{R}}{ }^{\mathrm{FixH}}$ of $1.01 \sim 1.06 \mathrm{kN}$ (different by $5.5 \%$ ) exceed the $P_{\max }(=0.332$ $\mathrm{kN})$. These results bear out the $\mathbf{G} 3$ statements.

- The predicted moment profiles using the current FreH and the previous FixH analyses (consistent with G2) bracket the measured moment response.

(1) The shear force profile of $\mathrm{CF}(\mathrm{FixH})$ (see Figure 14(b)) slightly deviates from that of the COM624P, as the LFP does (see Figure 13(a)).

(2) The moment profile of $\mathrm{CF}(\mathrm{FixH})$ compare with that of COM624P(FixH). Shifting the depth upward by an amount of $\mathrm{e}_{\mathrm{p}}(\mathrm{H} 2 \mathrm{~b})$, the revised moment profile of ' $\mathrm{CF}(\mathrm{FixH})$ corrected' agrees with the measured one (see Figure 14(c)), indicating again $w_{\mathrm{t}} \approx w_{\mathrm{g}}(\mathrm{H} 2 \mathrm{c})$.

(b) Group Piles

Responses of the 19 pile groups were predicted, in light of $N_{\mathrm{g}}=15.23, \alpha_{\mathrm{o}}=0 \mathrm{~m}, \mathrm{n}(=1.1$ 1.35), the $\mathrm{G}_{\mathrm{s}}$ and the $p$-multipliers provided in Table VI. In particular, shear modulus $G_{\mathrm{s}}$ for 13 out of the 19 groups was enlarged by 2-10 times compared to $0.3 \mathrm{MPa}$ for the single pile, to cater for the sand densification among the piles $\left(\right.$ G1) (e.g. $G_{\mathrm{s}}=3.0 \mathrm{MPa}$ for the $1 \times 3$ group at $\mathrm{s}=4 \mathrm{~d}$, etc). 
The predicted total load $\left(P_{\mathrm{g}}\right)$-deflection $\left(w_{\mathrm{g}}\right)$ curves (assuming FixH) of 15 groups are illustrated in Figures 15 and 16. (4 groups are not presented here as per notes in Table VI). They agree with the individually measured $P_{\mathrm{g}}-w_{\mathrm{t}}$ relationships (thus $w_{\mathrm{t}} \approx w_{\mathrm{g}}$ ). Bending moments for the piles in the $2 \times 3$ group were predicted and were found of similar accuracy to the experimental data (not presented herein). The slip depths under the specified deflection(s) $w_{\mathrm{g}}$ (see Table XIII) were evaluated for piles in each row and all groups, most of which are depicted in Figures 15 and 16 along with the load on each pile. At $w_{\mathrm{g}}=9.7 \mathrm{~mm}$ for the $1 \times 3$ group $(\mathrm{s}=4 \mathrm{~d})$, for instance, the limiting force was fully mobilised to a depth $x_{\mathrm{p}}$ of $18.5 \mathrm{~d}$ (LR), 20.9d (MR), and 22d(TR), respectively, under the calculated loads $(\mathrm{P})$ of $0.45 P_{\mathrm{g}}(\mathrm{LR}), 0.3 P_{\mathrm{g}}(\mathrm{MR})$ and $0.25 P_{\mathrm{g}}(\mathrm{TR})$. These values of $x_{\mathrm{p}}$ are $3 \sim 5$ times the $x_{\mathrm{p}}{ }^{\text {FreH }}(=6.47 \mathrm{~d})$ obtained for a free-head pile. A shallower depth $\left(x_{\mathrm{p}}\right)$ along the leading row than the trailing row piles is deduced, despite the former takes $80 \%$ more load. As the spacing s increases to $8 \mathrm{~d}$, the $x_{\mathrm{p}}$ reduces by $15-24 \%$, and the load distribution among rows tends to be even.

\section{(c) Individual Piles in 19 Groups}

To identify behaviour of individual piles, the reduction factor $R$ is calculated as the ratio of $N_{\mathrm{g}}$ for each pile in a group over that for a single isolated pile (ignoring the effect of $\mathrm{n}$ ). $N_{\mathrm{g}}$ and $R$ (see Table XIII) were deduced for individual piles in the 19 groups [33] by using the current FixH solutions to match load $(P)$-deflection $\left(w_{\mathrm{t}}\right)$ curve for each pile (N.B. ideally, measured $M_{\max }$ is needed as well for the back-estimation). The curve in turn was partitioned from the measured total load $P_{\mathrm{g}}-w_{\mathrm{t}}$ by stipulating an invariant $P / P_{\mathrm{g}}$ ratio (see Table XIII) during the course of loading test [30]. This presumption is justified as $N_{\mathrm{g}}$ and $R$ are independent of load levels. This $P / P_{\mathrm{g}}$ ratio is, as anticipated, different from that (shown in Figures 15 and 16) obtained previously using $p_{\mathrm{m}}$, so is the slip depth $x_{\mathrm{p}}$. Given a prescribed deflection for each group, the $P / P_{\mathrm{g}}$ ratio partitioned and depth 
$x_{\mathrm{p}}$ deduced are provided in Table XIII along with the average $R, \widetilde{R}$ for each row, (e.g. $\widetilde{R}$ for the Leading row, of the $3 \times 3$ group at $\mathrm{s}=4 \mathrm{~d}$, is $0.81[=(2+0.42) / 3])$. The $x_{\mathrm{p}}$, for instance in the $1 \times 3$ group $(\mathrm{s}=4 \mathrm{~d})$, changes from 18.5 22d (using $\mathrm{p}_{\mathrm{m}}$ ) to $17.8 \mathrm{~d}(\mathrm{LR}), 22.3 \mathrm{~d}(\mathrm{MR})$, and $27.5 \mathrm{~d}(\mathrm{TR})$, offering more non-uniform loads $(P)$ of $0.524 P_{\mathrm{g}}(\mathrm{LR}), 0.30 P_{\mathrm{g}}(\mathrm{MR})$, and $0.176 P_{\mathrm{g}}(\mathrm{TR})$, and unveiling the failure state of the trailing piles.

Table XIII allows the following conclusions to be drawn.

(1) At $\mathrm{s}=4 \mathrm{~d}\left(3 \times 3\right.$ group), $\widetilde{R}$ is $0.28(\mathrm{MR})$ and $0.42(\mathrm{TR})$, which is in opposite trend to the $p_{\mathrm{m}}$ of 0.4 and 0.3 (see Table VI) $[8,19,29,31,34]$, but with an identical total of 0.7 . At $\mathrm{s} \geq 8 \mathrm{~d}$, the $\widetilde{R}$ for either row is less than the $p_{\mathrm{m}}$ of $0.6-1.0$ [23] conventionally suggested.

(2) The $p_{\mathrm{m}}$ is sufficiently accurate for group response, but $R$ is needed for individual piles.

- The trailing Pile 31 in the $1 \times 3$, and the $2 \times 3$ groups $(s=4 d)$; and the pile 22 in the $3 \times 2$ group ( $\mathrm{s}=4 \mathrm{~d}$ ) attained full-slip along the shafts, as deduced using $R$, which are not revealed by the $p_{\mathrm{m}}$ (see Figures 15 and 16).

- $\quad$ Less load carried by the centre Pile 22 in the $3 \times 3$ group $(\mathrm{s}=4 \mathrm{~d}-8 \mathrm{~d})$ is well modelled using $R$ in the current solutions [33], as observed in centrifuge tests in clay [19]. The characteristic, however is not captured by the $\mathrm{FEM}^{3 \mathrm{D}}$ analysis [35], neither by the $\mathrm{p}_{\mathrm{m}}$ based analysis.

(3) The $M_{\max }$ in a leading row pile is more likely to reach structural limit prior to mobilising slip along the whole embedment. The reverse is true for a trailing row pile.

\section{Comments on current solutions}

The assumptions outlined in Table I have been justified previously for free-head piles [1], which are equally valid herein. Comments will be directed herein towards the impact of free-length, pilehead fixity restraint, pile-pile interaction, and failure mode of individual piles in a group. 
The study on the 6 single piles shows that as rotation constraint is released at a pile head,

(1) The $k$ increases (e.g. by $17 \sim 18 \%$ for the two examples). The $k$ (FixH), implicitly related to pile slenderness ratio $l / \mathrm{r}_{0}$ (Table II), becomes independent of the ratio for the FreH case [12]. Ignoring the coupled effect by using $N_{\mathrm{p}}=0$, the pile-head stiffness (FixH) is slightly overestimated, and it become slightly underestimated at the FreH case.

(2) The $N_{\mathrm{g}}$ increases by $200 \%$ (sand, Case IV) to $400 \%$ (clay, Case III), which lies in between $N_{\mathrm{g}}^{\text {FixH }}$ and $N_{\mathrm{g}}^{\text {FreH }}$ along a capped pile, to yield similar pile response; whereas the slip depth $x_{\mathrm{p}}$ reduces by $\sim 50 \%$. $T_{\mathrm{R}}$ may be calculated to check the input parameters.

The study on the 21 pile groups, along with comparison with $\mathrm{FLAC}^{3 \mathrm{D}}$ study on 3 pile groups (not shown herein), indicate that

(3) The $G_{\mathrm{s}}$ is $(17-76) \mathrm{s}_{\mathrm{u}}$ around 6 FixH pile groups in clay, which is $50 \%$ those for FreH piles. The $G_{\mathrm{s}}$ increases by 2-10 times (compared to single piles) for 13 of the 19 group piles in sand.

(4) The $p_{\mathrm{m}}$ allows load distributions among rows to be ascertained; whereas only the $R$ renders a true slip depth along each pile to be gauged. The $p_{\mathrm{m}}$ may be estimated using Equation (9). It is on safe side, especially with $\mathrm{s} / \mathrm{d}>8$.

(5) Maximum bending moment, $M_{\max }$ in capped piles was well predicted in light of FixH solutions and the $\mathrm{H} 2$ treatment. The prediction for a given deflection incorporates the components $P_{a v} \boldsymbol{e}_{\boldsymbol{p}}(\mathrm{H} 2 \mathrm{a})$ and $\mathrm{e}_{\mathrm{w}} \theta_{\mathrm{w}}(\mathrm{H} 2 \mathrm{c})$. The H2, intended for small $\mathrm{e}_{\mathrm{w}}$ and $\mathrm{e}_{\mathrm{p}}$ values, offers good simulation (not shown here) to a high eccentricity $\left(\mathrm{e}_{\mathrm{p}}=2.3 \mathrm{~m}\right)$ centrifuge test [23]. Unlike a rigid pile-cap stipulated herein, the alteration of bending moments with the cap stiffness cannot be captured using H2 [36], its calculation has to resort to complex numerical approaches [37]. 
(6) The $x_{\mathrm{p}}$, indicating the extent to limit state, increases $\sim 5$ times as the same loaded single (FreH) pile acts in a capped group, or as the same loaded pile shifts from a front row to a trailing row.

Nonlinear pile response for all cases is observed at a very low loading level and is dominated by the slip depth $x_{\mathrm{p}}$, as anticipated. It is well captured by the current solutions, in light of the modulus of $\mathrm{p}_{\mathrm{m}} k$ and the limiting force profile of $\mathrm{p}_{\mathrm{m}} p_{\mathrm{u}}\left(\mathrm{p}_{\mathrm{m}}=1\right.$ for a single pile). The $k$ and the $p_{\mathrm{u}}$ based on average soil parameters are sufficiently accurate for predicting piles in layered non-homogeneous soil. Neglecting the coupled interaction $\left(N_{\mathrm{p}} \neq 0\right)$, relevant solutions based on Winkler model (e.g. p-y curve method) underestimate pile deflection [1]. These outcomes were encapsulated into G1G5. Calculation of the solutions is much simpler than their appearance, and can be efficiently conducted. They may be entered into a spreadsheet. Or only the $w(x)$ and $w(z)$ (for predicting all response profiles) are required to be keyed in using a professional math program (e.g. MATHCAD). Other advantages over the p-y curve-based numerical solutions are identical to those highlighted for free-head piles [1].

Pertinent elastic analysis based on Winkler model should be gradually replaced with such nonlinear elastic-plastic solutions as these developed herein. Just as other methods, in using current solutions: (1) Care should be taken in determining $p_{u}$ profile concerning a thin stiffer surface layer [1]; and (2) Flexural stiffness should be reduced to cater to structural yielding [38].

\section{Conclusions}

Elastic-plastic solutions are developed for laterally loaded, infinitely long, fixed-head piles. They are presented in explicit closed-form expressions; and particularly for piles in sand in simple Equations (6) (8). They are employed to simulate nonlinear response of capped pile groups by 
adopting a new treatment $\mathrm{H} 2$ and $p$ - (or $R$ ) multiplier. The expressions were entered into a spreadsheet program GASLGROUP. With the solutions, nonlinear response of 6 single piles and 24 pile groups was well captured over the entire loading regime against numerical solutions and/or measured data. The impact of free-length, head-fixity, and group interaction is quantified, along with failure modes. The results are synthesized into the guidelines (G1-5). It should be noted that

- Nonlinear pile responses are characterised by the slip depth $x_{\mathrm{p}}$, and should be predicted. Existing p-y curve based approach generally overestimates the pile-head stiffness.

- Having similar accuracy to complex numerical approaches for layered non-homogeneous soil, the current calculations are readily conducted using a spreadsheet or a math program. With few parameters, they should be employed as a boundary element to simulate more complicated pile-soil interaction.

- The input parameters are readily deduced by matching the current solutions with measured pile response. As quality experimental data become available, this back-estimation should be continued to improve the guidelines, especially regarding the effect of group size on the $p_{\mathrm{m}}$.

- The remarkable impact of head restraint is captured well by the treatment H2. However, for important projects, more refined analysis incorporating pile-cap flexibility should be conducted.

Limited to elastic piles and static loading in this paper, the current solutions have also been successfully used for examining impact of cyclic loading. Being efficient in gaining nonlinear response of laterally loaded capped- piles and pile groups, the current solutions are tailored for routine design. 


\section{Acknowledgments}

The work reported here was sponsored by the Australian Research Council Discovery Grant (No. DP0209027). This financial assistance is gratefully acknowledged. The reviewers' comments have enabled the presentation to be improved. 


\section{APPENDIX I NOTATION}

The following symbols are used in the paper:

$A_{\mathrm{L}} \quad=$ coefficient for the LFP;

$c^{\prime} \quad=$ effective cohesion;

$d \quad=$ diameter of an equivalent solid cylinder pile;

$d_{\mathrm{o}} \quad=$ outside diameter of a pipe pile;

$D_{\mathrm{r}} \quad=$ relative density of sand;

$E_{\mathrm{p}} \quad=$ Young's modulus of an equivalent solid cylinder pile;

$e, e_{m}, e_{p}, e_{w}=$ eccentricity $\left(=e_{p}\right)$, eccentricity of the location above the ground level for measuring the $M_{\max }$, applying the $P\left(P_{g}\right)$, and measuring the $w_{\mathrm{t}}$;

FreH = free head, allowing translation and rotation at head-level;

FixH = fixed-head, allowing translation but not rotation at head level;

$G_{s}, \mathrm{G}^{*}=$ average soil shear modulus over the critical length, $L_{\mathrm{c}}$, and $\mathrm{G}^{*}=\left(1+0.75 \mathrm{v}_{\mathrm{s}}\right) \mathrm{G}_{\mathrm{s}}$;

$I_{\mathrm{p}} \quad=$ moment of inertia of an equivalent solid cylinder pile;

$k \quad=$ modulus of subgrade reaction;

$K_{\mathrm{i}}(\gamma)=$ modified Bessel function of second kind of $i^{\text {th }}$ order;

$K_{\mathrm{p}} \quad=\tan ^{2}\left(45^{\circ}+\phi^{\prime} / 2\right)$, passive earth pressure coefficient;

$L, L_{\mathrm{c}} \quad=$ embedded pile length, and critical length beyond which any increase in the embedment would not affect the pile response;

LFP $=$ the profile of net limiting force per unit pile length;

$\mathrm{LR}, \mathrm{MR}, \mathrm{TR}=$ leading row, middle row and trailing row;

$M_{\max }, M_{\mathrm{o}}, M(\bar{x})=$ maximum bending moment within a pile, and that occurs at the mudline level; the moment at the normalised depth $\bar{x}$;

$\bar{M}_{\max }=M_{\max } \lambda^{2+\mathrm{n}} / A_{L}$, normalised $M_{\max } ;$

$m \quad=$ row number

$N \quad=$ blow count of Standard Penetration Test (SPT);

$n, \mathrm{n}_{\mathrm{c}}{ }^{\mathrm{FreH}}, \mathrm{n}_{\mathrm{s}}{ }^{\mathrm{FixH}}=$ power for the LFP; $\mathrm{n}$ for free-head and fixed-head respectively. The subscripts $s$ and $c$ refer to sand and clay, respectively.

$N_{\mathrm{g}}, N_{\mathrm{g}}^{\mathrm{FreH}}, N_{\mathrm{g}}^{\mathrm{FixH}}=$ gradient correlated soil strength to the $\mathrm{p}_{\mathrm{u}}, N_{\mathrm{g}}$ for free- and fixed- head piles, respectively;

$N_{\mathrm{p}} \quad=$ fictitious tension for the membrane tied together the springs around the pile shaft;

$P, P_{\max }=$ lateral load exerted on a single pile, and maximum imposed $P$; 
$\bar{P} \quad=P \lambda^{1+\mathrm{n}} / A_{L}$, normalised pile-head load;

$P_{a v}, P_{g}=$ average load per pile in a group, and total load imposed on a group;

$P_{i j} \quad=$ pile number ij in a group $(\mathrm{i}=1-3, \mathrm{j}=1-2)$;

$p_{m} \quad=\mathrm{p}$-multipliers used to reduce stiffness, and limiting force for individual piles in a group;

$p_{\mathrm{u}} \quad=$ limiting force per unit length;

$p(\bar{x}), Q(\bar{x})=$ net force per unit length, and shear force at the normalised depth $\bar{x} ;$

$R(\widetilde{R})=$ ratio of $N_{\mathrm{g}}$ of a single pile in a group over that of the single pile (average of $R$ );

$s \quad=$ center-to-center spacing of piles in a group;

$s_{g} \quad=$ a comprehensive factor to account for variation in the $N_{\mathrm{g}}$;

$s_{\mathrm{u}}\left(\widetilde{s}_{u}\right)=$ undrained shear strength of soil (Average $s_{\mathrm{u}}$ over a maximum slip depth anticipated);

$t \quad=$ wall thickness of a pipe pile;

$T_{\mathrm{R}}=$ total resistance over the maximum slip depth $x_{\mathrm{p}}$ obtained under $P_{\max }$;

$x, x_{\mathrm{p}}, \bar{x}, \bar{x}_{p}=$ depth below ground level, slip depth from elastic to plastic state, $\bar{x}=\lambda x, \bar{x}_{p}=\lambda x_{\mathrm{p}}$;

$w, w(x), w(\mathrm{z})=$ lateral deflection of a pile, $w$ in the plastic, and $w$ in elastic zone, respectively;

$\bar{w}_{g} \quad=w_{\mathrm{g}} k \lambda^{\mathrm{n}} / A_{L}$ normalised mudline deflection;

$w_{\mathrm{p}} \quad=$ local limiting deflection beyond which the force mobilised on the depth is $p_{\mathrm{u}}$;

$w_{\mathrm{t}}, w_{\mathrm{g}}=$ pile deflection at loading level, and the deflection at mudline;

$w(\bar{x}), w^{\prime}(\bar{x})=$ deflection and rotation at the normalised depth $\bar{x} ;$

$z, \bar{z}=$ depth below the slip depth $x_{\mathrm{p}}$ (i.e. $z=x-x_{\mathrm{p}}$ ), and $\bar{z}=\lambda z$, respectively;

$\alpha_{0}\left(\bar{\alpha}_{o}\right)=$ an equivalent depth to account for ground level limiting force with $\bar{\alpha}_{o}=\alpha_{0} \lambda$;

$\alpha_{\mathrm{N}}, \beta_{\mathrm{N}}=$ normalised stiffness factors (Table IV);

$\gamma \quad=$ load transfer factor (Table II);

$\gamma_{\mathrm{s}}\left(\gamma_{s}^{\prime}\right)=$ unit weight of the overburden soil (effective $\gamma_{\mathrm{s}}$ );

$\theta_{\mathrm{w}} \quad=$ rotation angle of pile at the point of $\mathrm{e}_{\mathrm{w}} ;$

$\lambda=$ the reciprocal of characteristic length;

$v_{\mathrm{s}} \quad=$ Poisson's ratio of soil, taken as 0.25 for sand, otherwise 0.4 ;

$\phi\left(\phi^{\prime}\right)=$ angle of friction of soil (effective $\left.\phi\right)$. 


\section{References}

1. Guo, W.D., On limiting force profile, slip depth and lateral pile response. Computers and Geotechnics, 2006. 33(1): p. 47-67.

2. Guo, W.D. and F.H. Lee, Load transfer approach for laterally loaded piles. International Journal for Numerical and Analytical Methods in Geomechanics, 2001. 25(11): p. 11011129.

3. Sun, K., Laterally loaded piles in elastic media. Journal of Geotechnical Engineering Division, ASCE, 1994. 120(8): p. 1324-1344.

4. $\quad$ Scott, R.F., Foundation analysis. 1981, N. J.: Prentice Hall, Englewood Cliffs.

5. Duncan, J.M., M.D. Robinette, and R.L. Mokwa. Analysis of laterally loaded pile groups with partial pile head fixity. in Advances in Deep Foundations. 2005. GAS 132, ASCE.

6. Guo, W.D. Limiting force profile and laterally loaded pile groups. in Proceedings of $6^{\text {th }}$ International Conference on Tall Buildings. 2005. Hong Kong, China: World Scientific.

7. Ooi, P.S.K., B.K.F. Chang, and S. Wang, Simplified lateral load analyses of fixed-head piles and pile groups. Journal of Geotechnical and Geoenvironmental Engineering Division, ASCE, 2004. 130(11): p. 1140-11151.

8. Brown, D.A., C. Morrison, and L.C. Reese, Lateral load behaviour of pile group in sand. Journal of Geotechnical and Geoenvironmental Engineering Division, ASCE, 1998. 114(11): p. 1261-1276.

9. Viggiani, C. Ultimate lateral load on piles used to stabilise landslide. in Proceedings of the 10th International Conference on Soil Mechanics and Foundation Engineering. 1981. Stockholm, Sweden.

10. Broms, B., The lateral response of piles in cohesionless soils. Journal of Soil Mechanics and Foundation Engineering Division, ASCE, 1964. 90(3): p. 123-56.

11. Broms, B., The lateral response of piles in cohesive soils. Journal of Soil Mechanics and Foundation Engineering Division, ASCE, 1964a. 90(2): p. 27-63.

12. Guo, W.D. Response of laterally loaded rigid piles. in Proceedings of $12^{\text {th }}$ Pan-American conference on soil mechanics and Geotechnical engineering. 2003. MIT, Cambridge: Verlag Gluckauf GmbH.

13. Gazetas, G. and R. Dobry, Horizontal response of piles in layered soil. Journal of Geotechnical and Geoenvironmental Engineering Division, ASCE, 1984. 110(1): p. 20-40.

14. Syngros, K., Seismic response of piles and pile-supported bridge piers evaluated through case histories, in Civil Engineering. 2004, The City University of New York: London, U. K. p. 418.

15. Guo, W.D., Laterally loaded rigid piles in cohesionless soil. Canadian Geotechnical Journal, 2008. 45(5): p. 676-697.

16. Guo, W.D. and E.H. Ghee. Response of free-head piles due to lateral soil movement. in Proc. $9^{\text {th }}$ ANZ Conf. on Geomechanics. 2004. Auckland, New Zealand: New Zealand Geotechnical Society Inc.

17. Guo, W.D. and B.T. Zhu. Laterally loaded fixed-head piles in sand. in Proc. $9^{\text {th }}$ ANZ Conf. on Geomechanics. 2004. Auckland, New Zealand: New Zealand Geotechnical Society Inc. 
18. Yan, L. and P.M. Byrne, Lateral pile response to monotonic pile head loading. Canadian Geotechnical Journal, 1992. 29: p. 955-970.

19. IIyas, T., et al., Centrifuge model study of laterally loaded pile groups in clay. Journal of Geotechnical and Geoenvironmental Engineering Division, ASCE, 2004. 130(3): p. 274283.

20. Randolph, M.F. and G.T. Houlsby, The limiting pressure on a circular pile loaded laterally in cohesive soil. Geotechnique, 1984. 34(4): p. 613-623.

21. Hetenyi, M., Beams on elastic foundations. 1946, Ann Arbor: University of Michigan Press.

22. Mokwa, R.L. and J.M. Duncan, Discussion on 'Centrifuge model study of laterally loaded pile groups in clay' by T. IIyas, C. F. Leung, Y. K. Chow and S. S. Budi. Journal of Geotechnical and Geoenvironmental Engineering Division, ASCE, 2005. 131(10): p. 1305-1307.

23. Rollins, K.M., et al., Pile spacing effect on lateral pile group behaviour: Analysis. Journal of Geotechnical and Geoenvironmental Engineering Division, ASCE, 2006. 132(10): p. 1272-1283.

24. Dodds, A., A numerical study of pile behaviour in large pile groups under lateral loading. 2005, University of Southern Califoria: California.

25. Matlock, H., et al. Field tests of the lateral load behaviour of pile groups in soft clay. in Paper No. OTC. 3871, Proceedings of $12^{\text {th }}$ annual offshore technology conference. 1980. Houston, Texas.

26. Prakash, S. and H.D. Sharma, Pile foundations in engineering practice. 1989, New York, U. S. A.: John Wiley \& Sons, Inc.

27. Zhang, L.M., M.C. McVay, and P. Lai, Numerical analysis of laterally loaded $3 \times 3$ to $7 x$ 3 pile groups in sands. Journal of Geotechnical and Geoenvironmental Engineering Division, ASCE, 1999. 125(11): p. 936-946.

28. Wakai, A., S. Gose, and K. Ugai, 3-D Elasto-plastic finite element analyses of pile foundations subjected to lateral loading. Soils and Foundations, 1999. 39(1): p. 97-111.

29. Rollins, K.M., J.D. Lane, and T.M. Gerber, Measured and computed lateral resistance of a pile group in sand. Journal of Geotechnical and Geoenvironmental Engineering Division, ASCE, 2005. 131(1): p. 103-114.

30. Rollins, K.M., K.T. Peterson, and T.J. Weaver, Lateral load behaviour of full-scale pile group in clay. Journal of Geotechnical and Geoenvironmental Engineering Division, ASCE, 1998. 124(6): p. 468-478.

31. Ruesta, P.F. and F.C. Townsend, Evaluation of laterally loaded pile group at Roosevelt bridge. Journal of Geotechnical and Geoenvironmental Engineering Division, ASCE, 1997. 123(12): p. 1153-1161.

32. Gandhi, S.R. and S. Selvam, Group effect on driven piles under lateral load. Journal of Geotechnical and Geoenvironmental Engineering Division, ASCE, 1997. 123(8): p. 702709.

33. Guo, W.D. Laterally loaded rigid piles in Gibson soil. in Proceedings $2^{\text {rd }}$ International Conference on Structural Engineering Mechanics and Computation. 2004. Cape Town, South Africa. 
34. McVay, M., et al., Centrifuge testing of large laterally loaded pile. Journal of Geotechnical and Geoenvironmental Engineering Division, ASCE, 1998. 124(10): p. 1016-1026.

35. Yang, Z. and B. Jeremic, Numerical study of group effect for pile groups in sands. International Journal for Numerical and Analytical Methods in Geomechanics, 2003. 27(15): p. 1255-1276.

36. Won, J., et al., Nonlinear three-dimensional analysis of pile group supported columns considering pile cap flexibility. Computers and Geotechnics, 2006. 33(6-7): p. 355-370.

37. Poulos, H.G. and M.F. Randolph, Pile group analysis: A study of two methods. Journal of Geotechnical Engineering Division, ASCE, 1983. 109(3): p. 355-372.

38. Reese, L.C., Analysis of laterally loaded shafts in weak rock. Journal of Geotechnical and Geoenvironmental Engineering Division, ASCE, 1997. 123(11): p. 1010-1017. 
Table I Assumptions and features of current solutions

\begin{tabular}{|c|c|c|}
\hline Item & Assumptions & Features \\
\hline $\begin{array}{l}p-y \\
\text { curve } \\
\& x_{\mathrm{p}}\end{array}$ & $\begin{array}{l}\text { - The springs are characterized by an idealised elastic- } \\
\text { plastic } p-y \text { curve [y being rewritten as } w \text { in Figure 2(e)]. } \\
\text { The uncoupled and coupled load transfer models are } \\
\text { utilised to portray the plastic and elastic zones (Figure 1). }\end{array}$ & $\begin{array}{l}\text { - Plastic and elastic } \\
\text { zones encounter at } \\
\text { a depth } x_{\mathrm{p}} \text { called } \\
\text { slip depth }\end{array}$ \\
\hline $\begin{array}{l}G_{\mathrm{s}} \text { for } \mathrm{k} \\
\text { and } \mathrm{N}_{\mathrm{p}} \\
\mathrm{LFP}\end{array}$ & $\begin{array}{l}\text { - Average } G_{\mathrm{s}} \text { over a depth of } L_{\mathrm{c}} \text { is used to estimate the } k \\
\text { and } \mathrm{N}_{\mathrm{p}} \text { for elastic state; and } \\
\text { - Average soil properties over a maximum slip depth } \\
\text { (determined using G4) are employed to estimate the LFP } \\
\text { for plastic state. }\end{array}$ & $\begin{array}{l}\text { - } k \text { and } N_{\mathrm{p}} \text { deduced } \\
\text { from a soil } \\
\text { deflection mode. } \\
\text { - LFP given by } N_{\mathrm{g}} \text {, } \\
\alpha_{\mathrm{o}} \text {, and } n\end{array}$ \\
\hline $\begin{array}{l}\text { Plastic } \\
\text { zone }\end{array}$ & $\begin{array}{l}\text { - Interaction among the springs is negligible (i.e. } N_{\mathrm{p}}=0 \text {, } \\
\text { Figure 1). Pile deflection } w(x) \text { exceeds } w_{\mathrm{p}} \text { (see Figure } \\
\text { 2(d)), for which resistance per unit length, } p \text { is fully } \\
\text { mobilised. }\end{array}$ & $\begin{array}{l}N_{\mathrm{p}}=0 \\
w(x)>w_{\mathrm{p}} \\
p=p_{\mathrm{u}} .\end{array}$ \\
\hline$w_{\mathrm{p}}$ & $\begin{array}{l}\text { - At the slip depth, } x_{\mathrm{p}} \text {, the pile deflection } w(\mathrm{x}) \text { equals } w_{\mathrm{p}} \\
\text { (see Figure } 2(\mathrm{~d})) \text {. Below the } x_{\mathrm{p}} \text {, the deflection } w(\mathrm{z})<w_{\mathrm{p}} \text {; } \\
\text { and the resistance } p\left(<p_{\mathrm{u}}\right) \text { is linearly proportional to the } k \text {. }\end{array}$ & $\begin{array}{l}\text { - } w_{\mathrm{p}}=p_{\mathrm{u}} / \mathrm{k}, \text { shown in } \\
\text { Figure } 2(\mathrm{~d}) \\
\text { - } p=k w(\mathrm{z})\end{array}$ \\
\hline Slip & $\begin{array}{l}\text { - Pile-soil relative slip [e.g. value of } w(x)-w_{p} \text { ] can only be } \\
\text { initiated from mudline, and it can only move downwards. }\end{array}$ & $\begin{array}{l}\text { - Allowing closed- } \\
\text { form solutions to } \\
\text { be generated }\end{array}$ \\
\hline
\end{tabular}


Table II Load transfer model for single piles [1]

Parameters $\alpha_{0}, N_{\mathrm{g}}$, and $\mathrm{n}$ for LFP

(1) $p_{\mathrm{u}}$ is effective to the slip depth $x_{\mathrm{p}}$. Soil strength parameters $\mathrm{s}_{\mathrm{u}}$ (undrained shear strength), $N$ (blow count of SPT), and $\phi^{\prime}$ (effective angle of friction of soil) are calculated as the average values over the maximum $x_{\mathrm{p}}$. This max. $x_{p}$ initially is taken as $8 d$ for prototype piles, and $20 d$ for model piles

(2) FreH piles in cohesive soil: $\alpha_{\mathrm{o}}=0.05-0.2 \mathrm{~m}, N_{\mathrm{g}}$ $=0.6-4.8$ (average 1.6), and $n=0.7 \sim 1.7 . \mathrm{n}=0.7$ for a uniform strength profile; whereas $n=1.5$ 1.7 for a sharp increase strength profile (e.g. in stiff clay), otherwise, $\mathrm{n}$ is in the middle range (e.g. for a multi-layered soil). Given $n=\alpha_{0}=0$, the $\mathrm{p}_{\mathrm{u}}$ reduces to $\mathrm{s}_{\mathrm{u}} N_{\mathrm{g}} \mathrm{d}$, with $N_{\mathrm{g}}=2-4$ [9].

(3) FreH piles in sand: $N_{\mathrm{g}}=s_{\mathrm{g}} K_{\mathrm{p}}{ }^{2}, \alpha_{\mathrm{o}}=0$, and $n=$ 1.7 , where $K_{\mathrm{p}}=\tan ^{2}\left(45^{\circ}+\phi^{\prime} / 2\right)$, and $s_{\mathrm{g}}=0.3-2.0$ (average 1.12). High $s_{\mathrm{g}}$ is used to cater for dilatancy, which is less possible for FixH piles.

(4) In a layered soil, the $p_{\mathrm{u}}$ increases by $40 \%$ for a weak layer adjacent to a stiff layer. Conversely, it reduces by $30 \%$ for a stiff layer.

(5) LFP may be directly deduced from p-y curves.

(6) Matching 3 measured responses (e.g. $M_{\max }, w_{\mathrm{g}}$, and moment profile etc), $N_{\mathrm{g}}, \alpha_{\mathrm{o}}$ and $n$ are uniquely deduced using closed-form solutions, which capture overall nonlinear pile-soil interaction rather than soil response only [1].
$\mathrm{G}_{\mathrm{s}}, L_{\mathrm{c}}, k$, and $N_{\mathrm{p}}$ for elastic response

(a) $G_{s}=(25-340) s_{u}$ with an average of $92.3 s_{u}$. $G_{s}=(0.25-0.62) N(\mathrm{MPa})$ with an average of $0.5 N(\mathrm{MPa})$. The parameters $\mathrm{s}_{\mathrm{u}}$ and $N$ are calculated as the average values over the critical pile length $L_{\mathrm{c}}$ given by

(b)

$$
\frac{L_{c}}{r_{o}}=2.1\left[\frac{E_{p}}{G_{s}}\right]^{0.25}
$$

where $L_{c}$ is a critical pile length beyond which pile response is negligible; and $r_{o}$ is pile radius.

(c) $k=\frac{3 \pi G_{s}}{2}\left\{2 \gamma \frac{K_{1}(\gamma)}{K_{o}(\gamma)}-\gamma^{2}\left[\left(\frac{K_{1}(\gamma)}{K_{o}(\gamma)}\right)^{2}-1\right]\right\}$

where $K_{\mathrm{i}}(\gamma)$ is modified Bessel function of second kind of $i^{\text {th }}$ order $(i=0,1)$. The factor $\gamma$ for a sufficiently long fixed-head pile (i.e. $L$ in elastic zone $>L_{\mathrm{c}}$ ) is given by

$$
\gamma=0.65\left(E_{p} / G^{*}\right)^{-0.25}\left(L / r_{o}\right)^{-0.04}
$$

where $\mathrm{G}^{*}=\left(1+3 v_{\mathrm{s}} / 4\right) \mathrm{G}_{\mathrm{s}}$, generally $k=(2.4-$ 3.9) $G_{s}$ with an average of $3 G_{s}$ (clay) and $3.2 G_{s}$ (sand).

(d) $\quad N_{p}=\pi r_{o}^{2} G_{s}\left\lfloor\left(K_{1}(\gamma) / K_{o}(\gamma)\right)^{2}-1\right\rfloor$

These expressions may be readily estimated using a spreadsheet operating in $\mathrm{EXCEL}^{\mathrm{TM}}$ [2] 


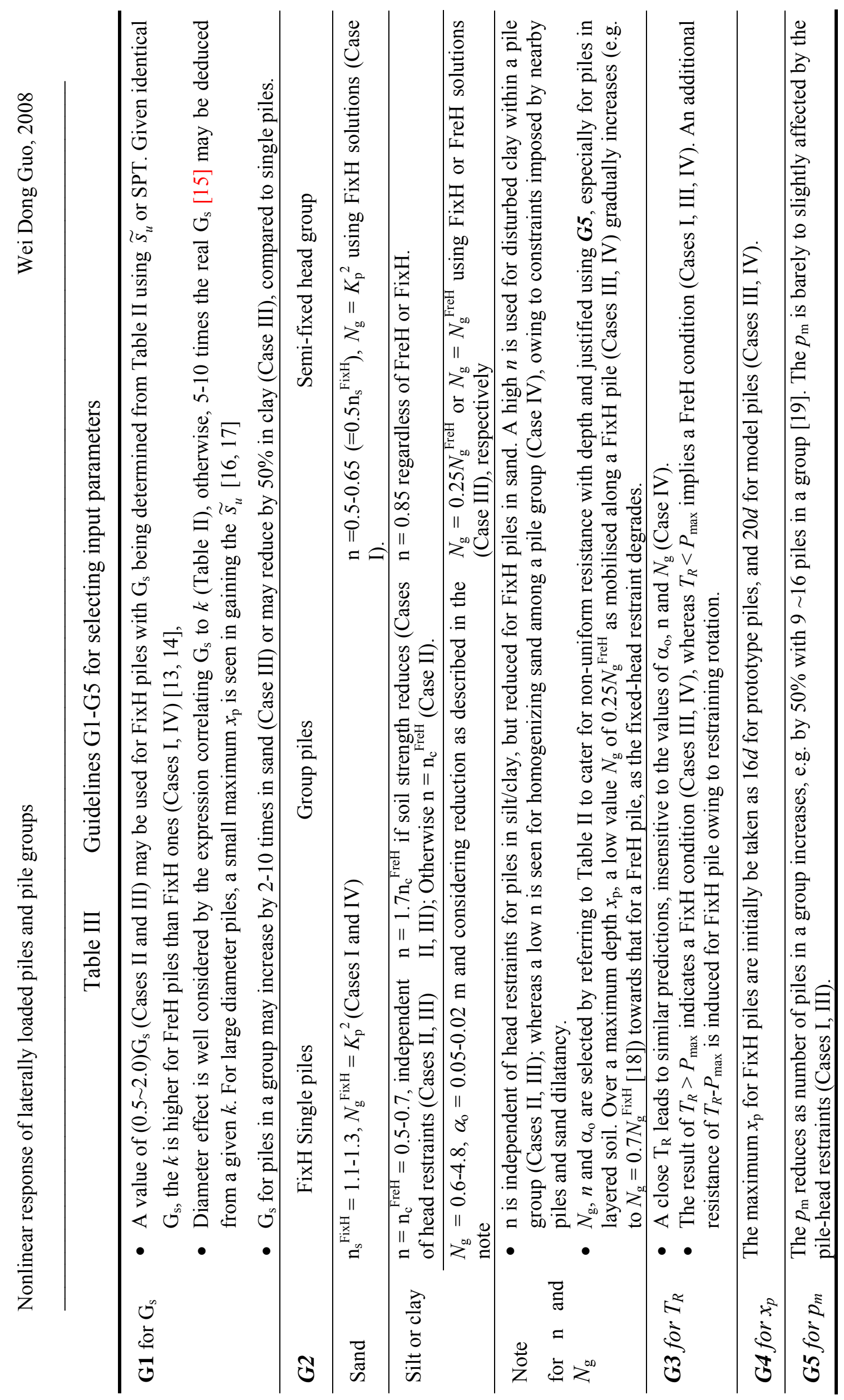

$\infty$ 
Table IV Expressions for response profiles of a fixed-head pile

Responses in plastic zone $\left(\bar{x} \leq \bar{x}_{p}\right)$

$$
\begin{aligned}
& w(\bar{x})=\frac{4 A_{L}}{k \lambda^{n}}\left[-F(4, \bar{x})+F(4,0)+F(3,0) \bar{x}+(F(1,0)+\bar{P}) \frac{\bar{x}^{3}}{6}+\bar{P} \bar{e} \frac{\bar{x}^{2}}{2}\right]+\frac{C_{2}}{\lambda^{2}} \frac{\bar{x}^{2}}{2} \\
& w^{\prime}(\bar{x})=\frac{4 A_{L} \lambda}{k \lambda^{n}}\left[-F(3, \bar{x})+F(3,0)+(F(1,0)+\bar{P}) \frac{\bar{x}^{2}}{2}+\bar{P} \bar{e} \bar{x}\right]+\frac{C_{2}}{\lambda} \bar{x} \\
& -M(\bar{x})=\frac{A_{L}}{\lambda^{2+n}}[-F(2, \bar{x})+(F(1,0)+\bar{P}) \bar{x}+\bar{P} \bar{e}]+C_{2} E_{p} I_{p} \\
& -Q(\bar{x})=\frac{A_{L}}{\lambda^{1+n}}[-F(1, \bar{x})+F(1,0)+\bar{P}]
\end{aligned}
$$

where $\bar{e}=\lambda e ; F(m, \bar{x})=\left(\bar{x}+\bar{\alpha}_{o}\right)^{n+m} /(n+m) \ldots(n+2)(n+1)(1 \leq \mathrm{m} \leq 4) ; \bar{\alpha}_{o}=\lambda \alpha_{0}$;

$$
\begin{aligned}
F(0, \bar{x})= & \left(\bar{x}+\bar{\alpha}_{o}\right)^{n} \\
C_{2}= & \left(-\alpha_{N} C_{5}+\beta_{N} C_{6}\right) \frac{\lambda^{2}}{\bar{x}_{p}}+\frac{4 A_{L} \lambda^{2}}{k \lambda^{n}}\left\{\left[F\left(3, \bar{x}_{p}\right)-F(3,0)\right] / \bar{x}_{p}-[F(1,0)+\bar{P}] \frac{\bar{x}_{p}}{2}-\bar{P}\right\} \\
C_{5}= & \frac{A_{L}}{k \lambda^{n}\left(\alpha_{N}+\bar{x}_{p}\right)}\left\{2\left(1-2 \alpha_{N}^{2}\right)\left[F(3,0)-F\left(3, \bar{x}_{p}\right)+\bar{x}_{p} F\left(2, \bar{x}_{p}\right)\right]\right. \\
& \left.-\left(1+2 \alpha_{N} \bar{x}_{p}\right) F\left(1, \bar{x}_{p}\right)+\left[1+2 \alpha_{N} \bar{x}_{p}-\left(1-2 \alpha_{N}^{2}\right) \bar{x}_{p}^{2}\right][F(1,0)+\bar{P}]\right\} \\
C_{6}= & \frac{A_{L}}{k \beta_{N} \lambda^{n}\left(\alpha_{N}+\bar{x}_{p}\right)}\left\{-2 \alpha_{N}\left(2 \alpha_{N}^{2}-3\right)\left[F(3,0)-F\left(3, \bar{x}_{p}\right)+\bar{x}_{p} F\left(2, \bar{x}_{p}\right)\right]\right. \\
& \left.-\left[\alpha_{N}+2\left(\alpha_{N}^{2}-1\right) \bar{x}_{p}\right] F\left(1, \bar{x}_{p}\right)+\left[\alpha_{N}+2\left(\alpha_{N}^{2}-1\right) \bar{x}_{p}+\alpha_{N}\left(2 \alpha_{N}^{2}-3\right) \bar{x}_{p}^{2}\right][F(1,0)+\bar{P}]\right\} \\
\alpha_{N}= & \sqrt{1+N_{p} / \sqrt{4 E_{p} I_{p} k}}, \beta_{N}=\sqrt{1-N_{p} / \sqrt{4 E_{p} I_{p} k}}
\end{aligned}
$$

Responses in elastic zone $\left(\bar{x}>\bar{x}_{p}\right.$, or $\left.\bar{z}>0, \bar{z}=\lambda z=\lambda\left(x-x_{p}\right)\right)$

$$
\begin{aligned}
& w(\bar{z})=e^{-\alpha_{N} \bar{z}}\left[C_{5} \cos \left(\beta_{N} \bar{z}\right)+C_{6} \sin \left(\beta_{N} \bar{z}\right)\right] \\
& w^{\prime}(\bar{z})=\lambda e^{-\alpha_{N} \bar{z}}\left[\left(-\alpha_{N} C_{5}+\beta_{N} C_{6}\right) \cos \left(\beta_{N} \bar{z}\right)+\left(-\beta_{N} C_{5}-\alpha_{N} C_{6}\right) \sin \left(\beta_{N} \bar{z}\right)\right] \\
& -M(\bar{z})=E_{p} I_{p} \lambda^{2} e^{-\alpha_{N} \bar{z}}\left\{\left[\left(\alpha_{N}^{2}-\beta_{N}^{2}\right) C_{5}-2 \alpha_{N} \beta_{N} C_{6}\right] \cos \left(\beta_{N} \bar{z}\right)+\left[2 \alpha_{N} \beta_{N} C_{5}+\left(\alpha_{N}^{2}-\beta_{N}^{2}\right) C_{6}\right] \sin \left(\beta_{N} \bar{z}\right)\right\} \\
& -Q(\bar{z})=E_{p} I_{p} \lambda^{3} e^{-\alpha_{N} \bar{z}}\left\{\left[-\alpha_{N}\left(\alpha_{N}^{2}-3 \beta_{N}^{2}\right) C_{5}+\beta_{N}\left(3 \alpha_{N}^{2}-\beta_{N}^{2}\right) C_{6}\right] \cos \left(\beta_{N} \bar{z}\right)\right. \\
& \left.\quad+\left[-\left(3 \alpha_{N}^{2}-\beta_{N}^{2}\right) \beta_{N} C_{5}-\alpha_{N}\left(\alpha_{N}^{2}-3 \beta_{N}^{2}\right) C_{6}\right] \sin \left(\beta_{N} \bar{z}\right)\right\}
\end{aligned}
$$

These expressions are independent of the head constraint, and are identical to those for freehead piles. 
Table $\mathrm{V} \quad \bar{P}, \bar{w}_{g}$ and $\bar{M}(\bar{x})$ of a fixed-head pile

(a) Normalised pile-head load, $\bar{P}$

$$
\begin{aligned}
\bar{P}= & -\frac{F\left(0, \bar{x}_{p}\right)\left(\bar{x}_{p}+\alpha_{N}\right)}{1-2 \alpha_{N}{ }^{2}-2 \alpha_{N} \bar{x}_{p}-\bar{x}_{p}^{2}}-\frac{\left[1-2 \alpha_{N}{ }^{2}-2 \alpha_{N} \bar{x}_{p}\right]\left[F(1,0)-F\left(1, \bar{x}_{p}\right)\right]}{1-2 \alpha_{N}{ }^{2}-2 \alpha_{N} \bar{x}_{p}-\bar{x}_{p}^{2}} \\
& -\frac{2\left[F(3,0)-F\left(3, \bar{x}_{p}\right)+\bar{x}_{p} F\left(2, \bar{x}_{p}\right)-0.5 F(1,0) \bar{x}_{p}^{2}\right]}{1-2 \alpha_{N}{ }^{2}-2 \alpha_{N} \bar{x}_{p}-\bar{x}_{p}^{2}}
\end{aligned}
$$

The $\bar{P}$ is deduced from the following relationship obtained for the depth, $x_{\mathrm{p}}(\mathrm{z}=0)$ : $\left(\alpha_{N}+\bar{x}_{p}\right) w_{P}^{I V}-\left(1-2 \alpha_{N}^{2}-2 \alpha_{N} \bar{x}_{p}\right) \lambda w_{P}^{\prime \prime \prime}-2 \lambda^{2}\left(\lambda w_{P}^{\prime}-\bar{x}_{p} w_{P}^{\prime \prime}\right)=0$

where $w_{p}^{\prime}, w_{p}^{\prime \prime}, w_{p}^{\prime \prime \prime}$, and $w_{p}^{I V}$ are values of $1^{\text {st }}, 2^{\text {rd }}, 3^{\text {th }}$, and $4^{\text {th }}$ derivatives of $w(x)$ with respect to depth $z$. Given $\bar{x}_{p}=0$, the minimum head load to initiate slip is obtained.

(b) Normalised mudline deflection, $\bar{w}_{g}$

$$
\begin{aligned}
\bar{w}_{g}= & 4\left[F\left(4, \bar{x}_{p}\right)-F(4,0)\right]-2 \bar{x}_{p}\left[F\left(3, \bar{x}_{p}\right)+F(3,0)\right] \\
& +\frac{2\left(1-2 \alpha_{N}^{2}-\alpha_{N} \bar{x}_{p}\right)}{\alpha_{N}+\bar{x}_{p}}\left[F(3,0)-F\left(3, \bar{x}_{p}\right)+\bar{x}_{p} F\left(2, \bar{x}_{p}\right)\right] \\
& -\frac{1+2 \alpha_{N} \bar{x}_{p}+\bar{x}_{p}^{2}}{\alpha_{N}+\bar{x}_{p}} F\left(1, \bar{x}_{p}\right)+\left(\frac{\bar{x}_{p}^{3}}{3}+\frac{1+2 \alpha_{N} \bar{x}_{p}+2 \alpha_{N}^{2} \bar{x}_{p}^{2}+\alpha_{N} \bar{x}_{p}^{3}}{\alpha_{N}+\bar{x}_{p}}\right)[F(1,0)+\bar{P}]
\end{aligned}
$$

Note $w_{\mathrm{g}}$ is deduced from $w(x)$ (see Table IV) (independent of e), along with $\mathrm{C}_{5}$ and $\mathrm{C}_{2}$.

(c) Normalised bending moment, $\bar{M}(\bar{x}) \quad\left(x<x_{\mathrm{p}}\right)$. The expression is deduced using expressions of $C_{j}(j=2,5$ and 6$)$ given in Table IV:

$-\bar{M}(\bar{x})=\frac{1}{\alpha_{N}+\bar{x}_{p}}\left[F\left(3, \bar{x}_{p}\right)-F(3,0)+\alpha_{N} F\left(2, \bar{x}_{p}\right)+0.5 F\left(1, \bar{x}_{p}\right)\right]+F(2, \bar{x})$

$+\left[\bar{x}-\frac{2 \alpha_{N} \bar{x}_{p}+\bar{x}_{p}^{2}+1}{2\left(\alpha_{N}+\bar{x}_{p}\right)}\right][F(1,0)+\bar{P}]$

Maximum bending moment $M_{\max }$ is obtained by substituting $\bar{x}=0$

Note: The constants $\mathrm{C}_{\mathrm{j}}$ are determined using the compatibility conditions of $Q(\bar{x}), M(\bar{x}), w^{\prime}(\bar{x})$, and $w(\bar{x})$ at the normalised slip depth, $\bar{x}_{p}\left[\bar{x}=\bar{x}_{p}\right.$ or $\left.\bar{z}=0\right]$. Elastic solutions validated for $N_{\mathrm{g}}<2\left(k E_{\mathrm{p}} I_{\mathrm{p}}\right)^{0.5}$ is ensured by $L$ being greater than the sum of $L_{\mathrm{c}}$ and the maximum $x_{\mathrm{p}}$ 
Table VI Parameters used for Cases I, II, and IV

\begin{tabular}{|c|c|c|c|c|c|c|c|c|}
\hline \multirow[t]{2}{*}{ References } & \multirow{2}{*}{$\begin{array}{c}G_{\mathrm{s}} \\
(\mathrm{MPa})\end{array}$} & \multirow[t]{2}{*}{ Group } & \multirow[t]{2}{*}{$\mathrm{s} / \mathrm{d}^{\mathrm{a}}$} & \multicolumn{4}{|c|}{$p_{m}$ by row } & \multirow{2}{*}{$\mathrm{n}$} \\
\hline & & & & $1^{\mathrm{st}}$ & $2^{\text {nd }}$ & $3^{\text {rd }}$ & $4^{\text {th }}$ & \\
\hline \multirow{2}{*}{$\begin{array}{l}\text { Case I: Model test [28] Sand: } \\
\phi=37.1^{\circ}, \gamma_{\mathrm{s}}=15.3 \mathrm{kN} / \mathrm{m}^{3}\end{array}$} & \multirow[t]{2}{*}{2.35} & $3 \times 3$ & 2.5 & 0.80 & 0.40 & 0.30 & & 0.58 \\
\hline & & $3 \times 3^{b}$ & 2.5 & 0.80 & 0.40 & 0.30 & & $1.15^{\mathrm{b}}$ \\
\hline $\begin{array}{l}\text { Case II: In situ test [28]: } \phi= \\
34.4^{\circ} \gamma_{s}^{\prime}=12.7 \mathrm{kN} / \mathrm{m}^{3}\end{array}$ & 10.2 & $3 \times 3$ & 2.5 & 0.80 & 0.40 & 0.30 & & $\begin{array}{c}0.85 \text { or } \\
1.20\end{array}$ \\
\hline \multirow[t]{2}{*}{ Case IV: } & \multirow{3}{*}{0.3} & \multirow{3}{*}{$1 \times 2$} & 4 & 0.80 & 0.80 & & & \multirow{3}{*}{1.35} \\
\hline & & & $8^{\mathrm{c}}$ & 0.90 & 0.90 & & & \\
\hline \multirow{4}{*}{$\begin{array}{l}\text { Model tests [32] } \\
\text { Sand: } \\
\phi=36.3^{\circ}\end{array}$} & & & 12 & 1.00 & 1.00 & & & \\
\hline & \multirow{3}{*}{3.0} & \multirow{3}{*}{$2 \times 2$} & 4 & 0.80 & 0.80 & & & \multirow{3}{*}{1.10} \\
\hline & & & $6^{\mathrm{c}}$ & 1.00 & 0.80 & & & \\
\hline & & & 8 & 1.00 & 1.00 & & & \\
\hline \multirow[t]{13}{*}{$\gamma_{\mathrm{s}}=14.6-17.3 \mathrm{kN} / \mathrm{m}^{3}$} & \multirow{3}{*}{0.8} & \multirow{3}{*}{$3 \times 2$} & 4 & 0.80 & 0.30 & & & \multirow{3}{*}{1.15} \\
\hline & & & $6^{c}$ & 0.80 & 0.35 & & & \\
\hline & & & 8 & 0.80 & 0.60 & & & \\
\hline & 3.0 & \multirow{3}{*}{$1 \times 3$} & 4 & 0.80 & 0.40 & 0.30 & & \multirow{3}{*}{1.20} \\
\hline & \multirow{2}{*}{0.3} & & $8^{c}$ & 0.90 & 0.70 & 0.60 & & \\
\hline & & & 12 & 1.0 & 0.80 & 0.80 & & \\
\hline & 0.8 & \multirow[b]{2}{*}{$2 \times 3$} & 4 & 0.80 & 0.40 & 0.30 & & \multirow[t]{2}{*}{1.25} \\
\hline & 3.0 & & 6 & 0.80 & 0.50 & 0.40 & & \\
\hline & \multirow{3}{*}{0.8} & \multirow{3}{*}{$3 \times 3$} & 4 & 0.80 & 0.40 & 0.30 & & \multirow{3}{*}{1.15} \\
\hline & & & 6 & 0.80 & 0.45 & 0.35 & & \\
\hline & & & 8 & 0.80 & 0.50 & 0.40 & & \\
\hline & 0.4 & $2 \times 1$ & 3 & 0.80 & & & & 1.35 \\
\hline & 0.3 & $3 \times 1$ & 3 & 0.80 & & & & 1.20 \\
\hline
\end{tabular}

Note: ${ }^{\mathrm{a}}$ Normalised center-to-center spacing in loading direction, but $\mathrm{s}=3 \mathrm{~d}$ within any row;

${ }^{\mathrm{b}}$ Free- head group; shear modulus $G_{\mathrm{s}}$ should be multiplied by $p_{\mathrm{m}}$ to gain modulus for a pile in a group.

${ }^{\mathrm{c}} p_{\mathrm{g}}-w_{\mathrm{g}}$ curve for $\mathrm{s} / \mathrm{d}=6$ or 8 (not shown here) lies in between those for $\mathrm{s} / \mathrm{d}=4$ and 8 or 4 and 12 , respectively. 
Table VII Pile properties and $\alpha_{\mathrm{o}}$ and $N_{\mathrm{g}}$ in current analysis

\begin{tabular}{c|c|c|c|c}
\hline Case & I & II & III & IV \\
\hline Pile length $(\mathrm{m})$ & 1.45 & 14.5 & 13.4 & 0.75 \\
\hline Diameter, $(\mathrm{m})$ & 0.05 & 0.319 & 0.084 & 0.0182 \\
\hline Flexural stiffness, $\left(\mathrm{MN}-\mathrm{m}^{2}\right)$ & $4.61 \times 10^{-3}$ & 5.623 & 2.326 & $86 \times 10^{-6}$ \\
\hline$\alpha_{o}$ for LFP, $(m)$ & 0 & 0 & Table X & 0 \\
\hline$N_{\mathrm{g}}$ for LFP & $K_{\mathrm{p}}^{2}$ & $2.4 K_{\mathrm{p}}^{2}$ & $1.0(\mathrm{FixH}), 4.0(\mathrm{FreH})$ & $(1-2) K_{\mathrm{p}}^{2}{ }^{\mathrm{a}}$ \\
\hline
\end{tabular}

Note: ${ }^{a} 1.0$ for single FixH piles, and group piles, and 2.0 for FreH single piles.

Table VIII A capped $3 \times 3$ group in sand at $w_{\mathrm{g}}=5 \mathrm{~mm}$ (Type A, Case I)

\begin{tabular}{ccccccc}
\hline Row & Measured $(\mathrm{kNm})$ & FEM $^{3 \mathrm{D}}(\mathrm{kNm})$ & \multicolumn{4}{c}{ Current predictions (GASLGROUP) } \\
\hline \multirow{2}{*}{ Leading $^{\mathrm{a}}$} & -0.148 & \multirow{2}{*}{-0.239} & $\mathrm{n}$ & $P_{a v}(\mathrm{kN})$ & $P_{a v} \mathrm{e}_{p}(\mathrm{kNm})$ & $M_{\mathrm{o}}(\mathrm{kNm})$ \\
\cline { 4 - 7 } & & & 0.58 & 0.959 & -0.048 & -0.250 \\
\cline { 4 - 7 } & & & 1.15 & 1.253 & -0.063 & -0.292 \\
\hline Back $^{\mathrm{a}}$ & -0.115 & -0.182 & 0.58 & 0.489 & -0.025 & -0.158 \\
\cline { 3 - 7 } & & & 1.15 & 0.464 & -0.023 & -0.182 \\
\hline
\end{tabular}

Note: 'a'Leading' refers to side pile (P11), \& 'Back' to middle pile (P32) shown in Figure 8.

Table IX A $3 \times 3$ pile group in sand (Type B, Case II)

\begin{tabular}{cccccccc}
\hline Load, $P_{\mathrm{g}}(\mathrm{kN})$ & \multicolumn{3}{c}{392} & \multicolumn{3}{c}{1570} \\
\hline Row number & & Leading & Middle & Trailing & Leading & Middle & Trailing \\
\hline Predicted load, $P_{\mathrm{av}}(\mathrm{kN})$ & $(1)$ & 62.04 & 37.86 & 30.78 & 240.53 & 154.51 & 128.5 \\
\hline Measured load, $\left.P_{\mathrm{av}}(\mathrm{kN})\right)^{\mathrm{a}}(2)$ & $\underline{48.81}$ & $\underline{41.2}$ & $\underline{40.68}$ & $\underline{271.86}$ & $\underline{150.88}$ & $\underline{112.92}$ \\
\hline$[(1)-(2)] /(2), \%$ & $(3)$ & 27.1 & -8.1 & -24.3 & -11.5 & 2.4 & 13.4 \\
\hline$M$ due to $e_{p}=1.3 \mathrm{~m}$ & $(4)$ & 80.65 & 49.22 & 40.0 & 312.69 & 200.86 & 167.05 \\
\hline GASLGROUP, $M_{\max }$ & $(5)$ & 46.93 & 33.33 & 28.87 & 297.51 & 220.57 & 199.69 \\
\hline Predicted $M_{o}(\mathrm{kNm})(4)+(5),(6)$ & 127.56 & 82.55 & 68.88 & 610.19 & 421.43 & 361.74 \\
\hline Measured $M_{o}(\mathrm{kNm})$ & $(7)$ & $\underline{112.48}$ & $\underline{84.36}$ & $\underline{84.35}$ & $\underline{674.84}$ & $\underline{492.07}$ & $\underline{393.74}$ \\
\hline$[(6)-(7)] /(7), \%$ & $(8)$ & -13.4 & -2.1 & -18.3 & -9.6 & -14.36 & -8.1 \\
\hline
\end{tabular}

Note: ${ }^{a}$ Calculated from reported load ratios of $1,0.843$, and 0.833 on leading, middle, and trailing rows at $P_{\mathrm{g}}=392 \mathrm{kN}$; and the ratios of $1,0.555$, and 0.37 at $P_{\mathrm{g}}=1570 \mathrm{kN}$, respectively. 
Table X In-situ tests on piles and pile groups in clay (Case III)

\begin{tabular}{|c|c|c|c|c|c|c|}
\hline \multicolumn{5}{|c|}{ Input parameters } & \multirow[b]{2}{*}{$p_{m}{ }^{\mathrm{a}}$} & \multirow{2}{*}{$\begin{array}{c}\text { Calculated parameters } \\
x_{\mathrm{p}} / \mathrm{d} @ P_{\max }\end{array}$} \\
\hline Items & $\mathrm{G}_{\mathrm{s}} / \mathrm{s}_{\mathrm{u}}$ & $n^{\mathrm{a}}$ & $\alpha_{0}(m)^{a}$ & $N_{\mathrm{g}}$ & & \\
\hline Single pile & $50(100)^{b}$ & 0.55 & 0.05 & $1.0(4 .)^{b}$ & 1.0 & $15.1(8.0)^{b}$ \\
\hline 5-pile group & $75(100)$ & 0.85 & 0.05 & $1.0(4)$. & 0.333 & $19.6(11.3)$ \\
\hline 10-pile group & $17(33)$ & 0.85 & 0.25 & $1.0(4)$. & 0.20 & $23.2(12.1)$ \\
\hline
\end{tabular}

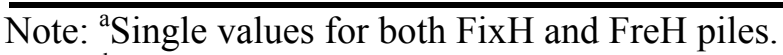

${ }^{b}$ Values without (e.g. 50) and with parenthesis (e.g. 100) are for FixH and FreH, respectively.

Table XI Parameters for elastic response of single piles in sand (Case IV)

\begin{tabular}{cccccccc}
\hline & Input data & \multicolumn{6}{c}{ Calculated parameters (as per expressions in Table II) } \\
\cline { 1 - 7 } Items & $\mathrm{G}_{\mathrm{s}}(\mathrm{kPa})$ & $\gamma$ & $k(\mathrm{kPa})$ & $N_{\mathrm{p}} /\left(2 \mathrm{E}_{\mathrm{p}} \mathrm{I}_{\mathrm{p}}\right)$ & $\alpha_{\mathrm{N}}$ & $\beta_{\mathrm{N}}$ & $\lambda\left(\mathrm{m}^{-1}\right)$ \\
\cline { 1 - 5 } FixH & \multirow{2}{*}{300} & 0.03805 & 711.7 & 26.71 & 1.1373 & 0.8425 & 6.7443 \\
\cline { 5 - 8 } FreH & & 0.06872 & 831.1 & 11.62 & 1.0575 & 0.9390 & 7.0109 \\
\hline
\end{tabular}

Table XII Parameters for plastic response for single piles in sand (Case IV)

\begin{tabular}{|c|c|c|c|c|c|c|c|}
\hline \multirow[b]{2}{*}{ Items } & \multicolumn{3}{|c|}{ Input data } & \multicolumn{4}{|c|}{ Calculated (plastic) parameters } \\
\hline & $n$ & $\alpha_{o}(m)$ & $s_{\mathrm{g}}$ & $N_{\mathrm{g}}$ & $A_{L}\left(\mathrm{kPa} / \mathrm{m}^{\mathrm{n}}\right)$ & $x_{\mathrm{p}} / \mathrm{d} @ P(\mathrm{kN})$ & $T_{R}(\mathrm{kN})$ \\
\hline FixH & & 0 & 0.45 & 6.86 & 33.41 & $12.55 @ 0.332$ & 1.005 \\
\hline FreH $^{b}$ & 1.7 & 0 & 2.0 & 30.45 & 148.50 & $6.47 @ 0.255$ & 0.171 \\
\hline FixH $^{a, b}$ & 1.35 & 0 & 1.0 & 15.23 & 18.26 & $12.6 @ 0.332$ & 1.060 \\
\hline FreH $^{\mathrm{a}}$ & & 0.05 & 1.0 & 15.23 & 18.26 & $10.85 @ 0.255$ & 0.165 \\
\hline
\end{tabular}


Table XIII Prediction of response of individual piles in 19 groups ${ }^{\text {a }}$ (Case IV)

\begin{tabular}{|c|c|c|c|c|c|c|c|c|c|c|}
\hline \multirow{2}{*}{$\begin{array}{l}\text { Group } \\
1 \times 2\end{array}$} & \multirow{2}{*}{$\frac{\mathrm{s} / \mathrm{d}}{4}$} & \multirow{2}{*}{$\begin{array}{c}\text { Pile }^{\mathrm{c}} \\
11\end{array}$} & \multirow{2}{*}{$\begin{array}{l}P / P_{\mathrm{g}} \\
0.636\end{array}$} & \multicolumn{2}{|c|}{$G_{\mathrm{s}}(\mathrm{MPa}) n$} & \multirow{2}{*}{$\begin{array}{c}N_{\mathrm{g}} \\
\underline{15.23} \\
\end{array}$} & \multirow{2}{*}{$\begin{array}{l}R \\
1\end{array}$} & \multirow{2}{*}{$\begin{array}{l}N_{\mathrm{g}} / K_{\mathrm{p}} \\
3.91\end{array}$} & \multirow{2}{*}{$\begin{array}{c}\widetilde{R} \\
1\end{array}$} & \multirow{2}{*}{$\frac{x_{\mathrm{p}} / d\left[x_{\mathrm{p}} / d\right] @ w_{\mathrm{g}}(\mathrm{mm})}{12.4[12.9] @ 11.2}$} \\
\hline & & & & 0.3 & 1.35 & & & & & \\
\hline & & 21 & 0.364 & & & 4.87 & 0.32 & 1.25 & .32 & 17.7[12.9]@11.2 \\
\hline \multirow[t]{4}{*}{ O० $\rightarrow$} & 8 & 11 & 0.558 & & & $\underline{15.23}$ & 1 & 3.91 & 1 & 12.4[12.6]@11.2 \\
\hline & & 21 & 0.442 & & & $\overline{9.14}$ & 0.6 & 2.34 & .60 & 14.7[12.6]@11.2 \\
\hline & 12 & 11 & 0.515 & & & 15.23 & 1 & 3.91 & 1 & 12.4[12.9]@11.2 \\
\hline & & 21 & 0.485 & & & $\overline{13.86}$ & 0.91 & 3.55 & .91 & 12.8[12.9]@11.2 \\
\hline \multirow{2}{*}{$2 \times 1$ 웅 } & -- & 11 & 1 & & 1.35 & $\underline{15.23}$ & 1 & 3.91 & & \\
\hline & & $11^{\mathrm{b}}$ & 1 & 0.4 & & $\overline{12.64}$ & 0.83 & 3.23 & .92 & \\
\hline \multirow[t]{3}{*}{$1 \times 3$} & 4 & 11 & 0.524 & 3.0 & 1.2 & $\underline{15.23}$ & 1 & 3.91 & 1 & 17.8[18.5]@9.7 \\
\hline & & 21 & 0.300 & & & $\overline{6.09}$ & 0.4 & 1.56 & .40 & 22.3[20.9]@9.7 \\
\hline & & 31 & 0.176 & & & 2.44 & 0.16 & 0.63 & .16 & $27.5[22.0] @ 9.7^{\mathrm{e}}$ \\
\hline \multirow[t]{6}{*}{$000 \rightarrow$} & 8 & 11 & 0.414 & 0.3 & & $\underline{15.23}$ & 1 & 3.91 & 1 & 15.5[15.7]@15.2 \\
\hline & & 21 & 0.328 & & & 9.14 & 0.6 & 2.34 & .60 & 18.2[16.3]@15.2 \\
\hline & & 31 & 0.258 & & & 5.79 & 0.38 & 1.48 & .38 & 20.8[16.7]@15.2 \\
\hline & 12 & 11 & 0.370 & 0.3 & & $\underline{15.23}$ & 1 & 3.91 & 1 & 15.5[15.5]@15.2 \\
\hline & & 21 & 0.349 & & & $\overline{13.71}$ & 0.9 & 3.52 & .90 & 16.1[16.1]@15.2 \\
\hline & & 31 & 0.281 & & & 8.83 & 0.58 & 2.26 & .58 & 18.4[16.1]@15.2 \\
\hline \multirow{2}{*}{$3 \times 1$ 回 } & --- & 11 & 0.383 & 0.3 & & $\underline{15.23}$ & 1 & 3.91 & & \\
\hline & & $12^{b}$ & 0.233 & & & 5.79 & 0.38 & 1.48 & .79 & \\
\hline \multirow[t]{2}{*}{$\overline{2 \times 2}$} & 4 & 11 & 0.281 & 3.0 & 1.2 & $\underline{15.23}$ & 1 & 3.91 & 1 & 19.8[20.6]@11.2 \\
\hline & & 21 & 0.219 & & & 9.90 & 0.65 & 2.54 & .65 & 22.0[20.6]@11.2 \\
\hline \multirow{4}{*}{ ○০ } & 6 & 11 & 0.268 & 3.0 & & $\underline{15.23}$ & 1 & 3.91 & 1 & 19.8[18.6]@11.2 \\
\hline & & 21 & 0.232 & & & $\overline{11.73}$ & 0.77 & 3.01 & .77 & 21.1[19.4]@11.2 \\
\hline & 8 & 11 & 0.256 & 3.0 & & $\underline{15.23}$ & 1 & 3.91 & 1 & 19.8[19.8[@11.2 \\
\hline & & 21 & 0.244 & & & 14.47 & 0.95 & 3.71 & .95 & 20.0[19.8[@11.2 \\
\hline \multirow[t]{2}{*}{$\overline{2 \times 3}$} & 4 & 11 & 0.238 & 0.3 & 1.25 & $\underline{15.23}$ & 1 & 3.91 & 1 & 14.9[20.0]@15.2 \\
\hline & & 21 & 0.186 & & & 9.44 & 0.62 & 2.42 & .62 & 17.3[22.6]@15.2 \\
\hline \multirow{4}{*}{ ০০০ } & & 31 & 0.077 & & & 1.98 & 0.13 & 0.51 & .13 & 27.5[23.7]@15.2 \\
\hline & 6 & 11 & 0.199 & & & $\underline{15.23}$ & 1 & 3.91 & 1 & 14.9[20.0]@15.2 \\
\hline & & 21 & 0.172 & & & $\overline{11.42}$ & 0.75 & 2.93 & .75 & 16.3[21.7]@15.2 \\
\hline & & 31 & 0.129 & & & 6.40 & 0.42 & 1.64 & .42 & 19.4[22.6]@15.2 \\
\hline
\end{tabular}


Table XIII Prediction of response of individual piles in 19 groups (Cont's) (Case IV)

\begin{tabular}{|c|c|c|c|c|c|c|c|c|c|c|}
\hline Group & $\mathrm{s} / \mathrm{d}$ & Pile & $P / P_{\mathrm{g}}$ & $G_{\mathrm{s}}(\mathrm{MPa})$ & $n$ & $N_{\mathrm{g}}$ & $R$ & $N_{\mathrm{g}} / K_{\mathrm{p}}$ & $\widetilde{R}$ & $x_{\mathrm{p}} / d\left[x_{\mathrm{p}} / d\right] @ w_{\mathrm{g}}(\mathrm{mm})^{\mathrm{d}}$ \\
\hline \multirow[t]{3}{*}{$3 \times 2$} & \multirow[t]{4}{*}{4} & 11 & 0.246 & \multirow[t]{12}{*}{0.8} & \multirow[t]{4}{*}{1.15} & $\underline{15.23}$ & 1 & 3.91 & \multirow{3}{*}{803} & 17.0[17.6]@11.2 \\
\hline & & $12^{b}$ & 0.150 & & & 6.24 & 0.41 & 1.60 & & 21.6[17.6]@11.2 \\
\hline & & 21 & 0.138 & & & 5.48 & 0.36 & 1.41 & & 22.3[20.6]@11.2 \\
\hline \multirow{9}{*}{$\begin{array}{ll}\text { :여 } \\
\text { ००० }\end{array}$} & & $22^{b}$ & 0.084 & & & 2.28 & 0.15 & 0.58 & .29 & $27.5[20.6] @ 11.2^{\mathrm{e}}$ \\
\hline & 6 & 11 & 0.232 & & \multirow[t]{4}{*}{1.15} & $\underline{15.23}$ & 1 & 3.91 & & 17.0[17.5]@11.2 \\
\hline & & $12^{b}$ & 0.141 & & & $\overline{6.09}$ & 0.4 & 1.56 & .80 & 21.7[17.5]@11.2 \\
\hline & & 21 & 0.151 & & & 6.85 & 0.45 & 1.76 & & 21.1[20.0]@11.2 \\
\hline & & $22^{b}$ & 0.092 & & & 2.89 & 0.19 & 0.74 & .36 & 26.3[20.0]@11.2 \\
\hline & \multirow[t]{4}{*}{8} & 11 & 0.199 & & \multirow[t]{4}{*}{1.15} & $\underline{15.23}$ & 1 & 3.91 & & 17.0[17.5]@11.2 \\
\hline & & $12^{b}$ & 0.121 & & & $\overline{6.09}$ & 0.4 & 1.56 & .80 & 21.7[17.5]@11.2 \\
\hline & & 21 & 0.180 & & & 12.79 & 0.84 & 3.28 & & 17.8[18.3]@11.2 \\
\hline & & $22^{b}$ & 0.110 & & & 5.18 & 0.34 & 1.33 & .67 & 22.7[18.3]@11.2 \\
\hline \multirow[t]{6}{*}{$\overline{3 \times 3}$} & \multirow[t]{6}{*}{4} & 11 & 0.169 & \multirow[t]{6}{*}{0.8} & \multirow[t]{6}{*}{1.15} & 15.23 & 1 & 3.91 & \multirow{3}{*}{.81} & $15.5[16.1] @ 8.2$ \\
\hline & & $12^{b}$ & 0.103 & & & $\overline{6.40}$ & 0.42 & 1.64 & & 19.8[16.1]@8.2 \\
\hline & & 21 & 0.095 & & & 5.33 & 0.35 & 1.37 & & 20.7[18.0]@8.2 \\
\hline & & $22^{b}$ & 0.058 & & & 2.28 & 0.15 & 0.58 & \multirow[t]{2}{*}{.28} & 25.8[18.0]@8.2 \\
\hline & & 31 & 0.119 & & & 7.92 & 0.52 & 2.03 & & 18.6[18.8]@8.2 \\
\hline & & $32^{b}$ & 0.073 & & & 3.35 & 0.22 & 0.86 & \multirow[t]{2}{*}{.42} & 23.4[18.8]@8.2 \\
\hline \multirow{12}{*}{ 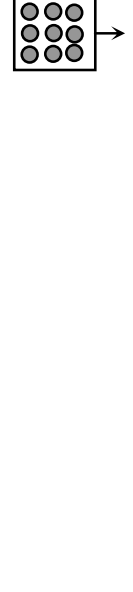 } & \multirow[t]{6}{*}{6} & 11 & 0.163 & & \multirow[t]{6}{*}{1.15} & $\underline{15.23}$ & 1 & 3.91 & & 15.5[16.2]@8.2 \\
\hline & & $12^{b}$ & 0.099 & & & 6.55 & 0.43 & 1.68 & \multirow[t]{2}{*}{.81} & 19.6[16.2]@8.2 \\
\hline & & 21 & 0.106 & & & 7.31 & 0.48 & 1.87 & & 19.1[17.7]@8.2 \\
\hline & & $22^{b}$ & 0.064 & & & 3.05 & 0.2 & 0.78 & \multirow[t]{2}{*}{.39} & 24.0[17.7]@8.2 \\
\hline & & 31 & 0.115 & & & 8.38 & 0.55 & 2.15 & & 18.4[18.4]@8.2 \\
\hline & & $32^{b}$ & 0.070 & & & 3.50 & 0.23 & 0.90 & \multirow[t]{2}{*}{.44} & 23.2[18.4]@8.2 \\
\hline & \multirow[t]{6}{*}{8} & 11 & 0.159 & & \multirow[t]{6}{*}{1.15} & $\underline{15.23}$ & 1 & 3.91 & & 15.5[16.1]@8.2 \\
\hline & & $12^{b}$ & 0.097 & & & $\overline{6.55}$ & 0.43 & 1.68 & \multirow[t]{2}{*}{.81} & 19.6[16.1]@8.2 \\
\hline & & 21 & 0.144 & & & 12.95 & 0.85 & 3.32 & & 16.3[17.3]@8.2 \\
\hline & & $22^{b}$ & 0.088 & & & 5.48 & 0.36 & 1.41 & \multirow[t]{2}{*}{.69} & 20.6[17.3]@8.2 \\
\hline & & 31 & 0.081 & & & 4.72 & 0.31 & 1.21 & & 21.4[18.0]@8.2 \\
\hline & & $32^{b}$ & 0.049 & & & 2.28 & 0.15 & 0.58 & .26 & 25.8[18.0]@8.2 \\
\hline
\end{tabular}

Note: ${ }^{\mathrm{a}}$ This table was developed from reference [33]. ${ }^{\mathrm{b}}$ Middle pile in a row; others are side piles. ${ }^{\mathrm{c}}$ Pile number is shown in Figures 15 and $16 ;{ }^{\mathrm{d}}$ The $x_{\mathrm{p}} / \mathrm{d}\left[x_{\mathrm{p}} / \mathrm{d}\right]$ was estimated using $R\left[p_{\mathrm{m}}\right.$ in Table VI] for the specified deflection, $w_{\mathrm{g}} .{ }^{\mathrm{e}}$ Limiting force was fully mobilized along the pile length. 


\section{Figure Captions}

Figure 1 Schematic model for a laterally loaded fixed-head pile

Figure 2 Schematic limiting force and deflection profiles

Figure 3 Schematic profiles of on-pile force and bending moment

Figure 4. Calculation flow chart for current solutions (e.g. GASLGROUP)

Figure 5 Determination of $p$-multiplier $p_{\mathrm{m}}$

Figure 6. Two typical pile-head constraints investigated and $\mathrm{H} 2$ treatment

Figure 7 The current solutions compared to the model tests, and $\mathrm{FEM}^{3 \mathrm{D}}$ results [28]: Case I

Figure 8 The current solutions compared to the group pile test, and $\mathrm{FEM}^{3 \mathrm{D}}$ results [28]: Case I

Figure 9 Predicted $P_{\mathrm{g}}(P)-w_{\mathrm{g}}$ vs measured $P_{\mathrm{g}}(P)-w_{\mathrm{t}}$ response of the pile and pile group [28]: Case II

Figure 10 LFPs for the single pile, 5- and 10-pile groups [25]: Case III

Figure 11 Predicted vs measured [25] response of the single pile, 5- and 10-pile groups: Case III

Figure 12 Predicted vs. measured [25] moment profiles of single pile and 10-pile groups: Case III

Figure 13 Predicted vs. measured [32] response of the driven piles: CASE IV

Figure 14 Predicted versus measured [32] response of the driven piles at 10-mm deflection: Case IV

Figure 15 Predicted $P_{\mathrm{g}}-w_{\mathrm{g}}$ vs. measured [32] $P_{\mathrm{g}}-w_{\mathrm{t}}$ response of various groups: Case IV (2rows)

Figure 16 Predicted $P_{\mathrm{g}}-w_{\mathrm{g}}$ vs. measured [32] $P_{\mathrm{g}}-w_{\mathrm{t}}$ response of various groups: Case IV (3rows) 


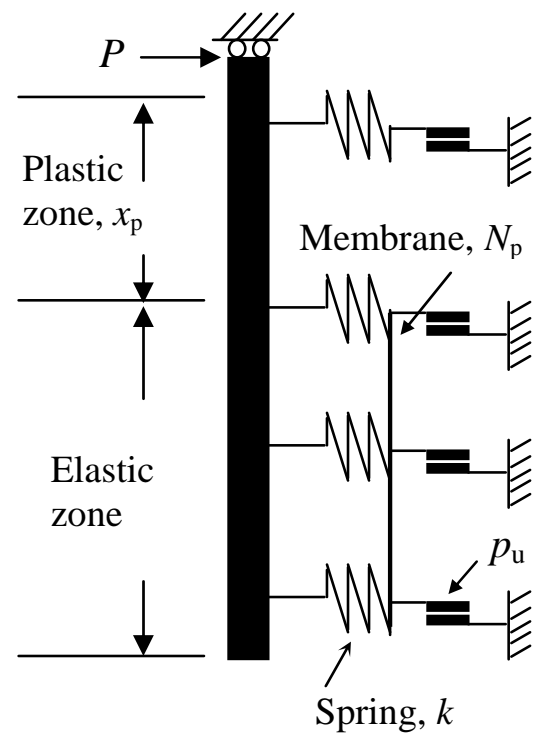

Figure 1. Schematic model for a laterally loaded fixed-head pile

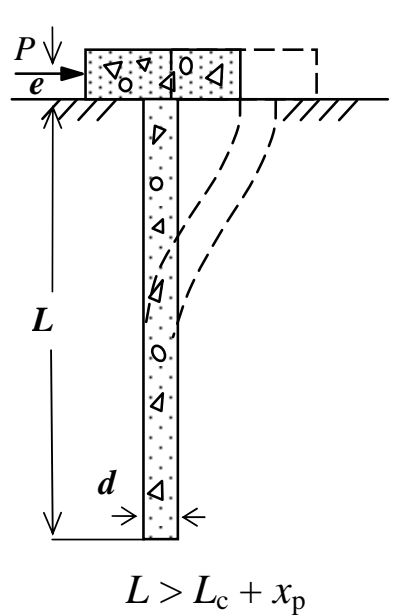

(a) Single pile

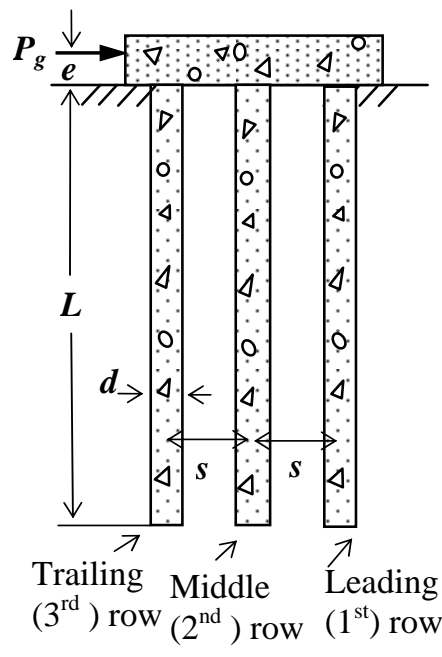

(b) Piles in a group

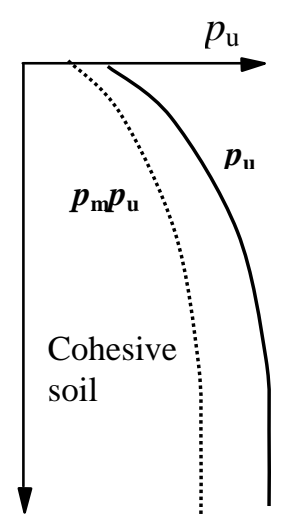

(c) LFP

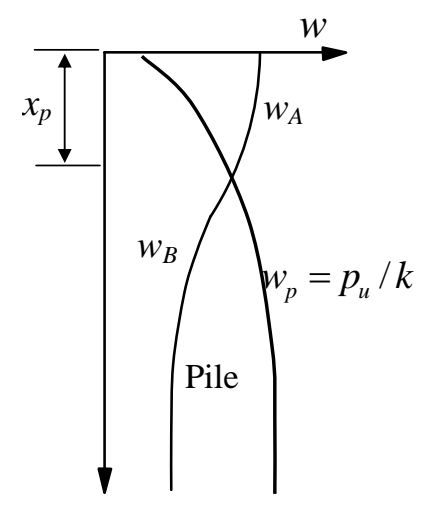

(d) Pile deflection $\& w_{p}$ profiles

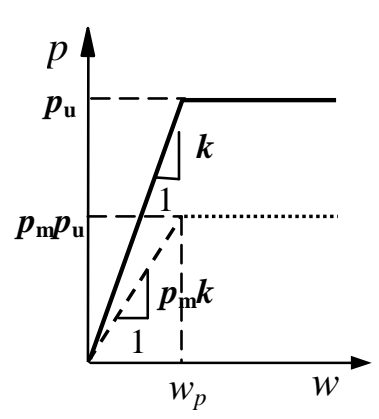

(e) $p$ - y curve for a single pile $\&$ piles in a group

Figure 2. Schematic limiting force and deflection profiles 

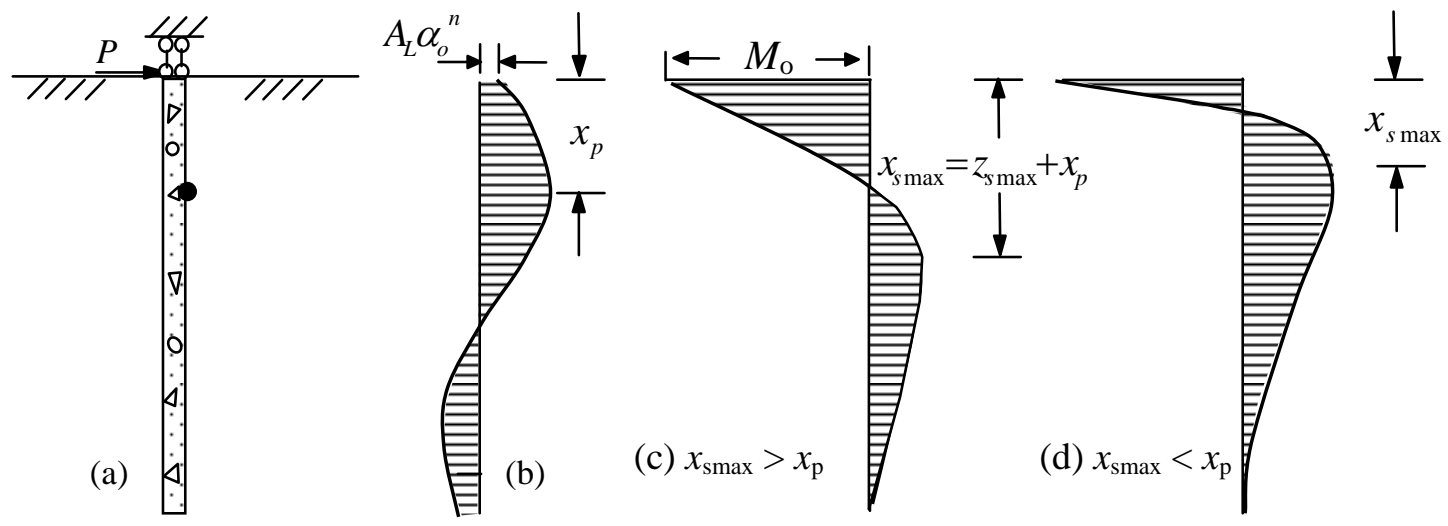

Note: $x_{\text {smax }} \quad=$ depth of second maximum bending moment

$z_{\text {smax }}=$ depth of second maximum bending moment occurred below $x_{\mathrm{p}}$

Figure 3. Schematic profiles of on-pile force and bending moment

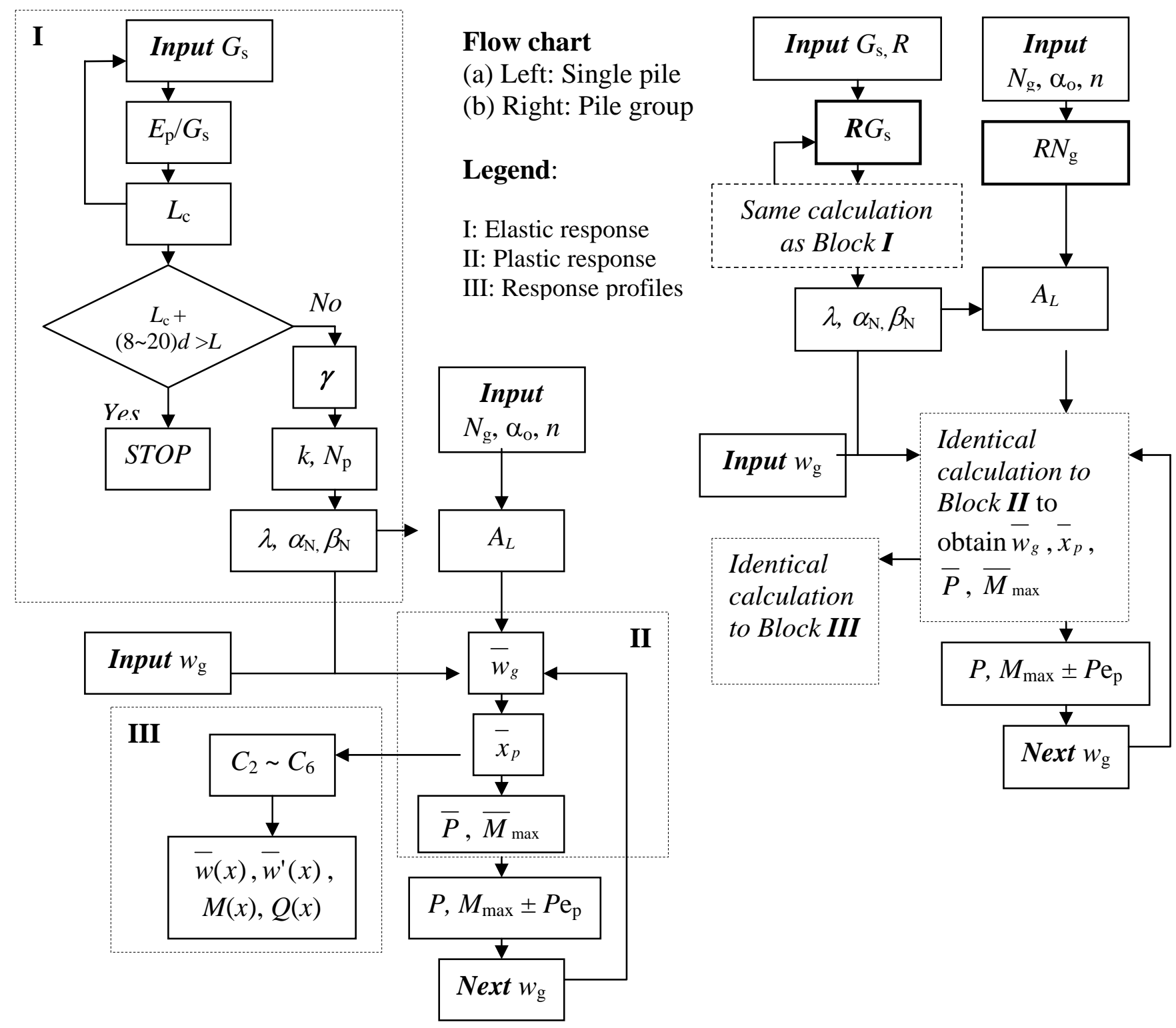

Figure 4. Calculation flow chart for current solutions (e.g. GASLGROUP) 


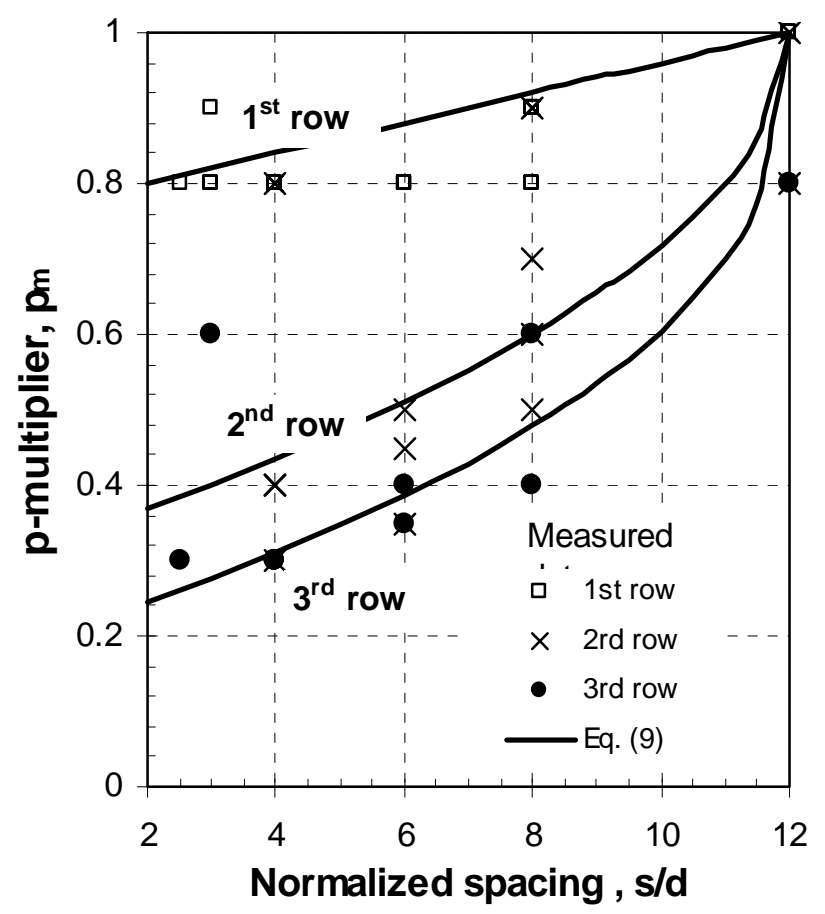

(a) Equation (9) versus $p_{m}$ derived from current study

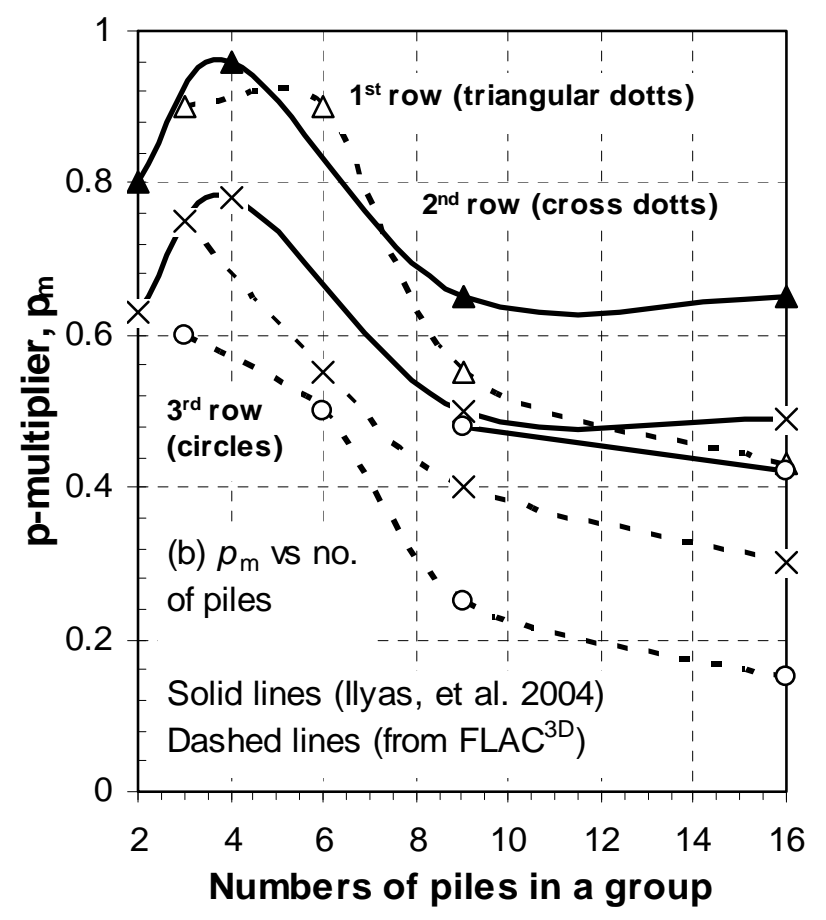

(b) Reduction in $\mathrm{p}_{\mathrm{m}}$ with number of piles in a group

Figure 5 Determination of $p$-multiplier $\mathrm{p}_{\mathrm{m}}$ 


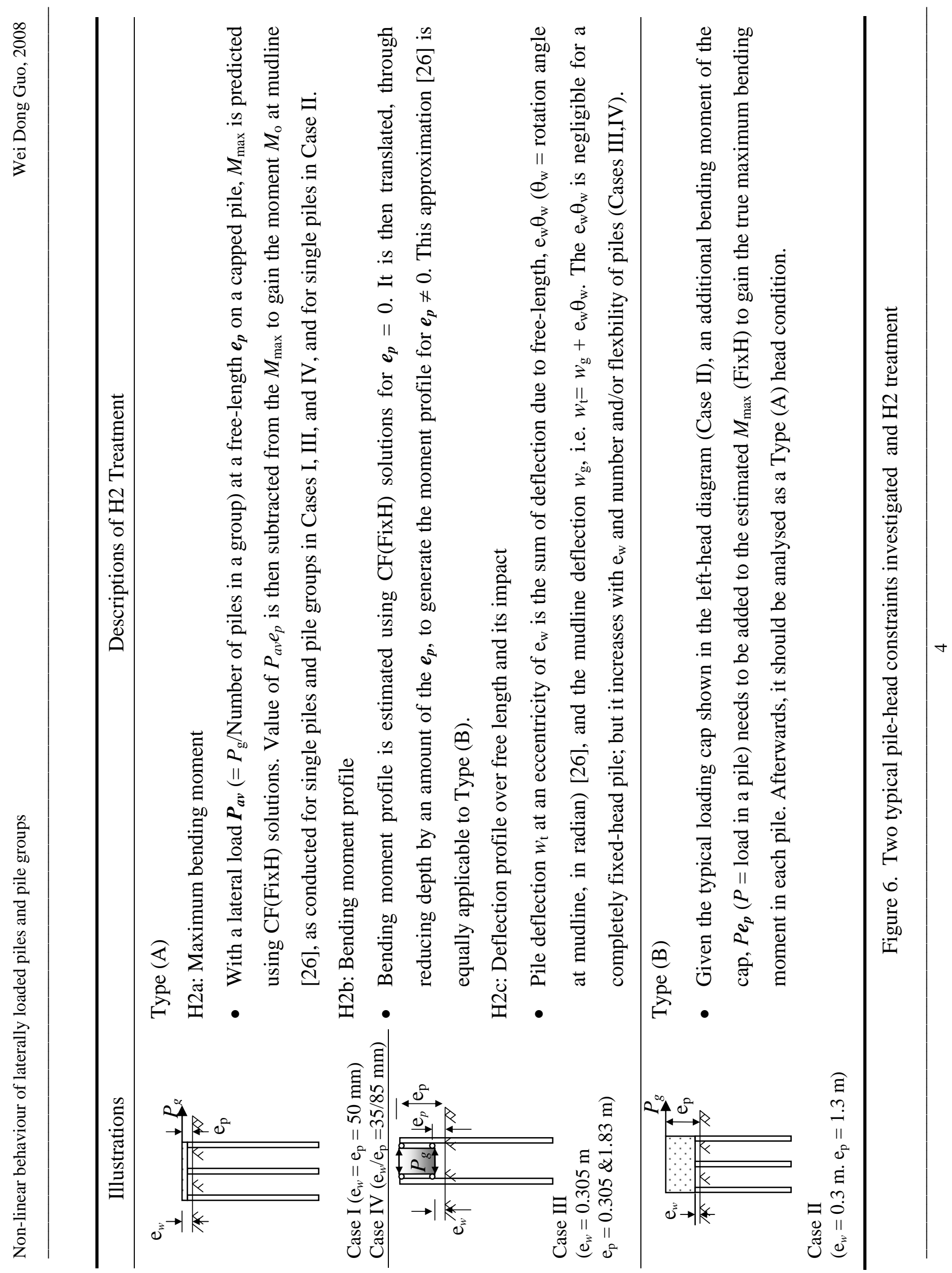



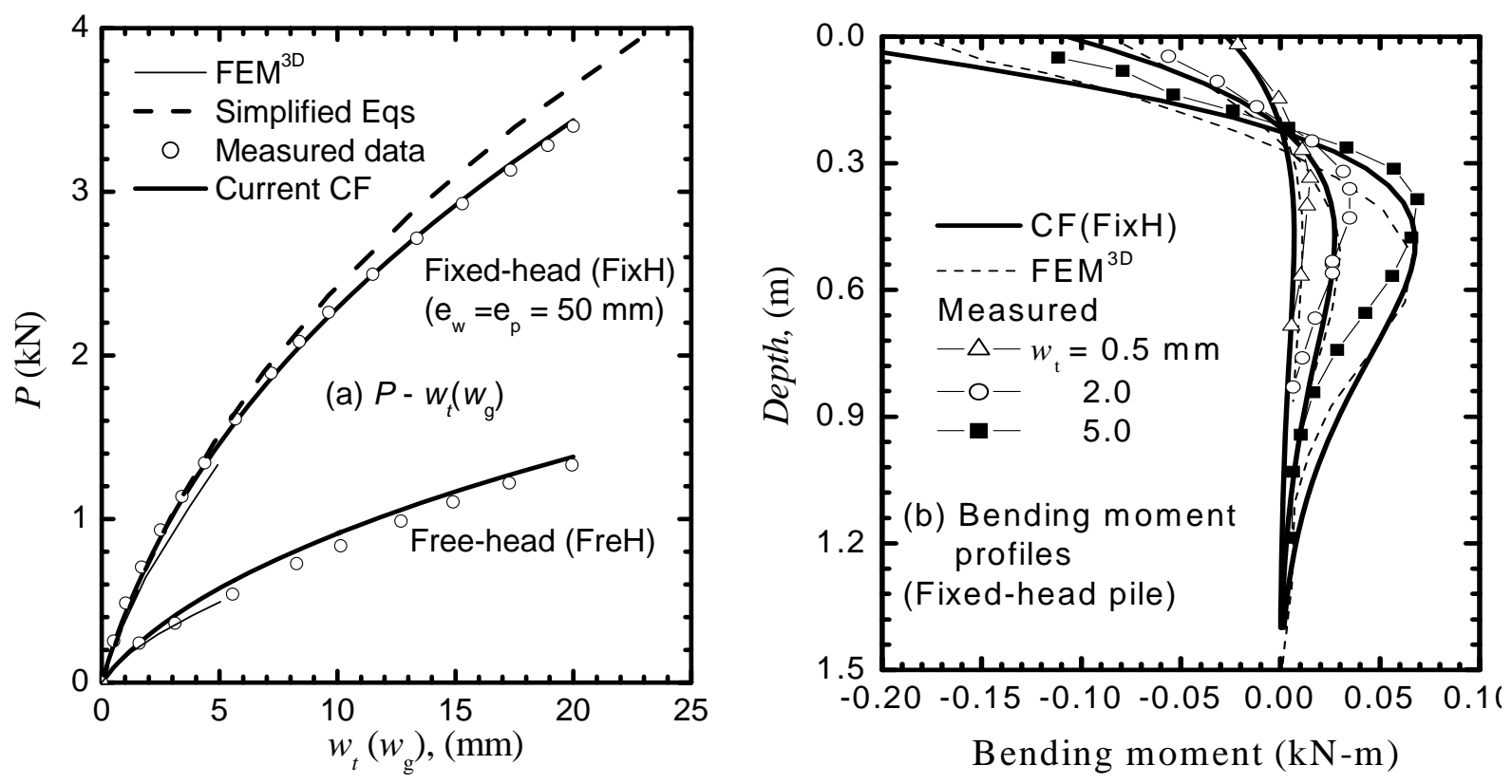

Figure 7. The current solutions compared to the model tests, and $\mathrm{FEM}^{3 \mathrm{D}}$ results [21]: Case I

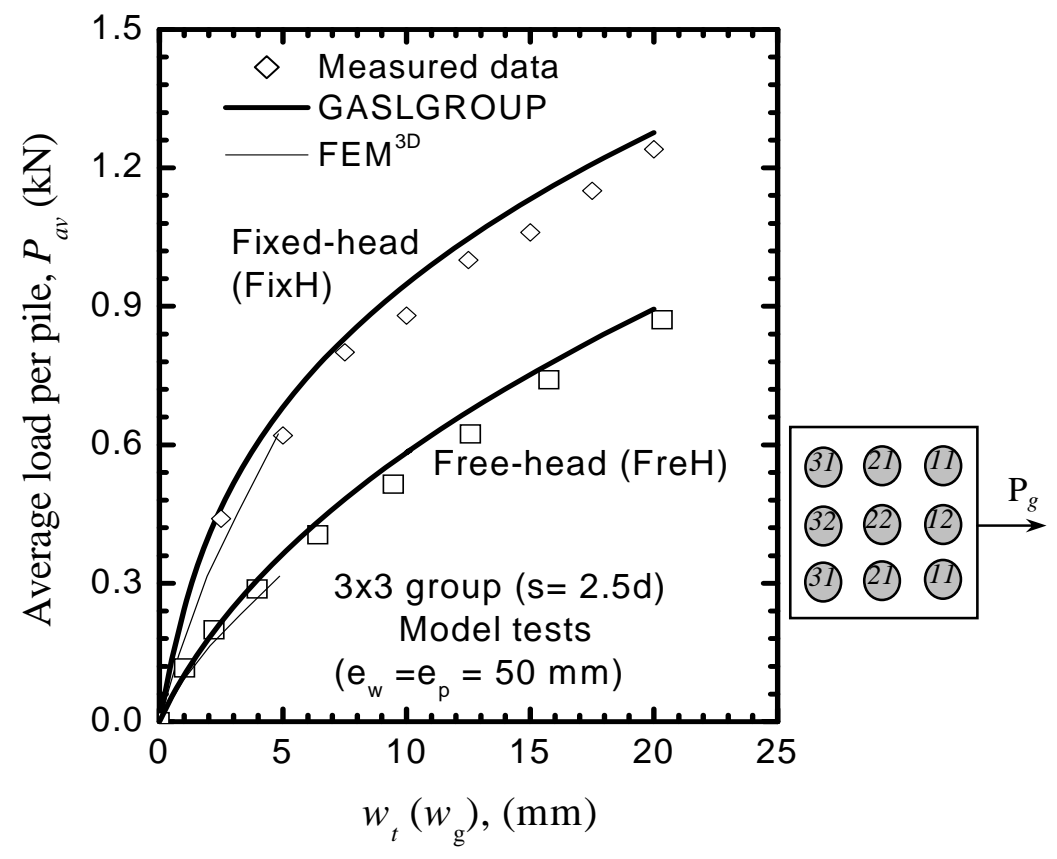

Figure 8. The current solutions compared to the group pile tests, and $\mathrm{FEM}^{3 \mathrm{D}}$ results [21]: Case I 

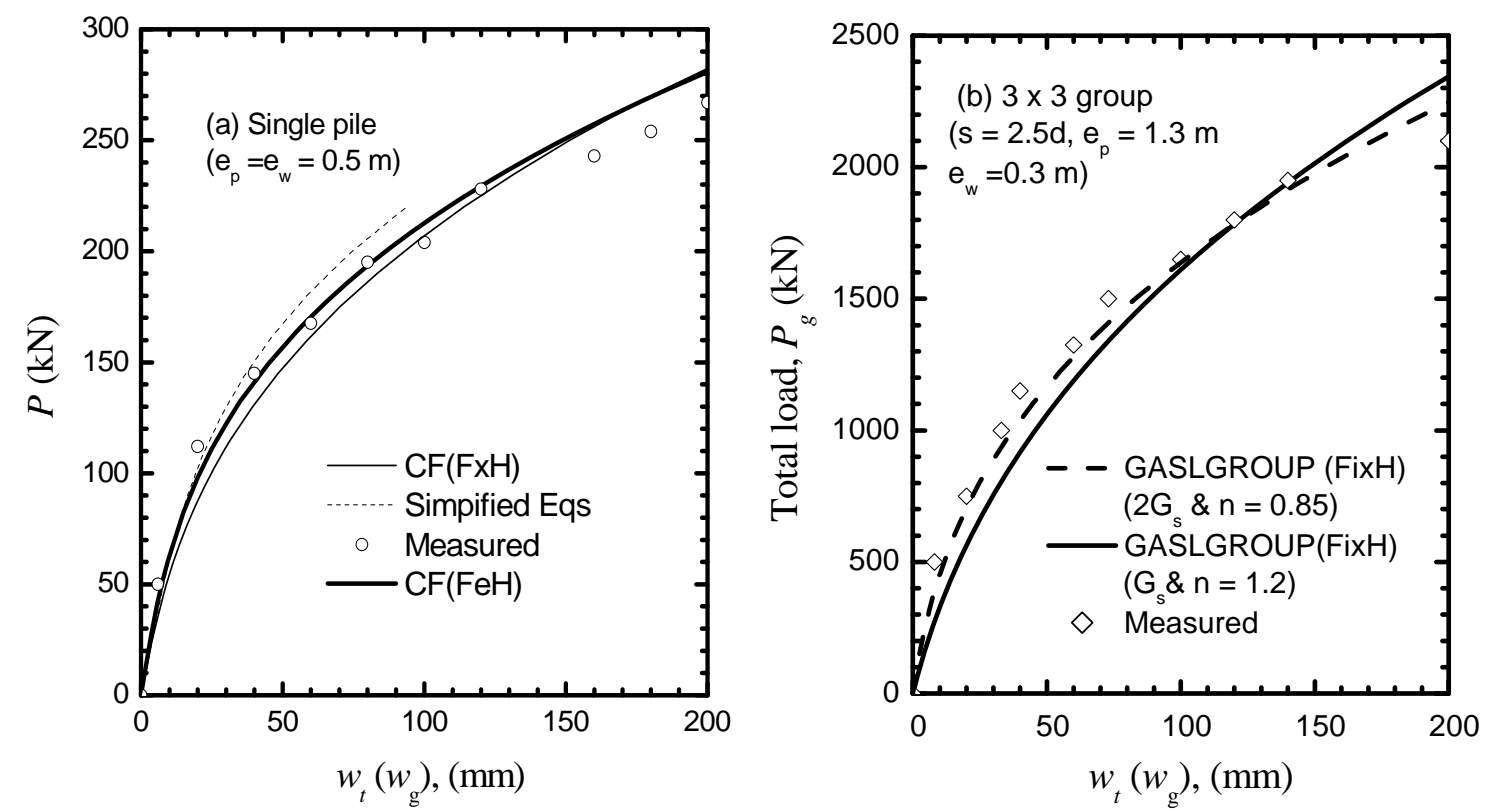

Figure 9. Predicted $P_{\mathrm{g}}(P)-w_{\mathrm{g}}$ vs measured $P_{\mathrm{g}}(P)-w_{\mathrm{t}}$ response of the pile and pile group [20]: Case II

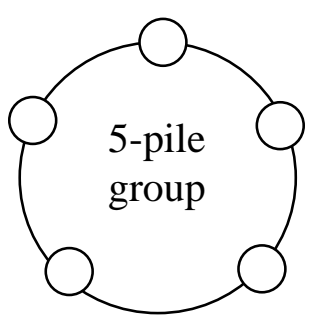

(a) Layout of the pile groups
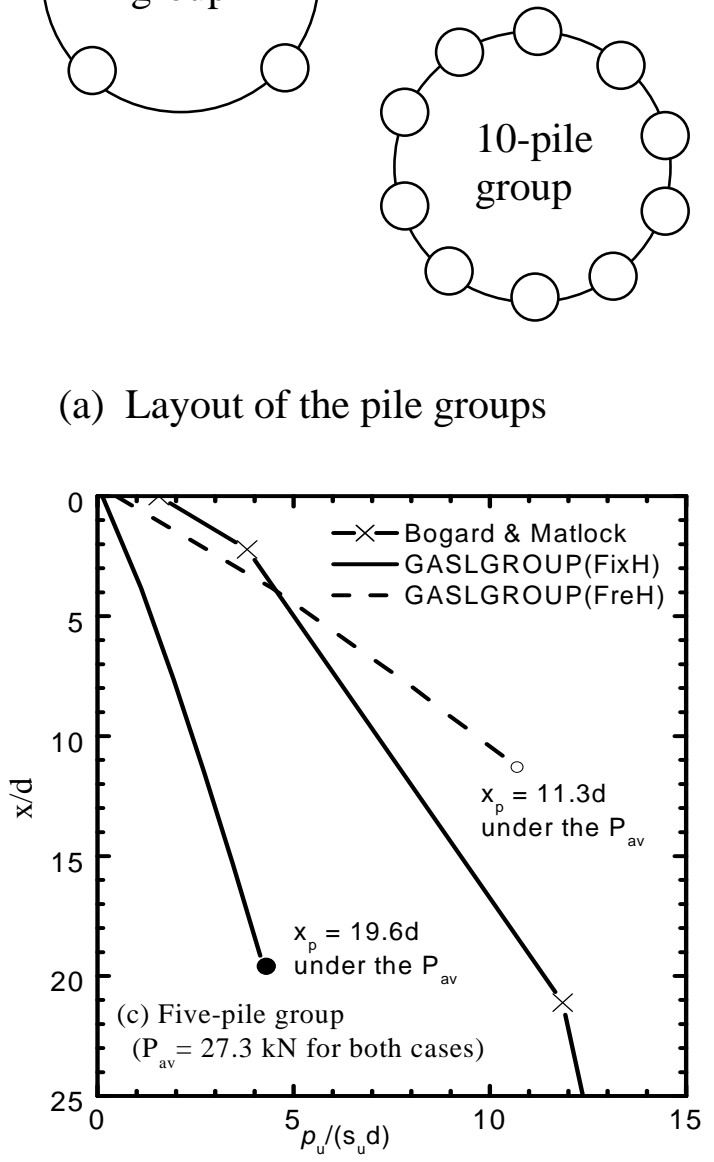

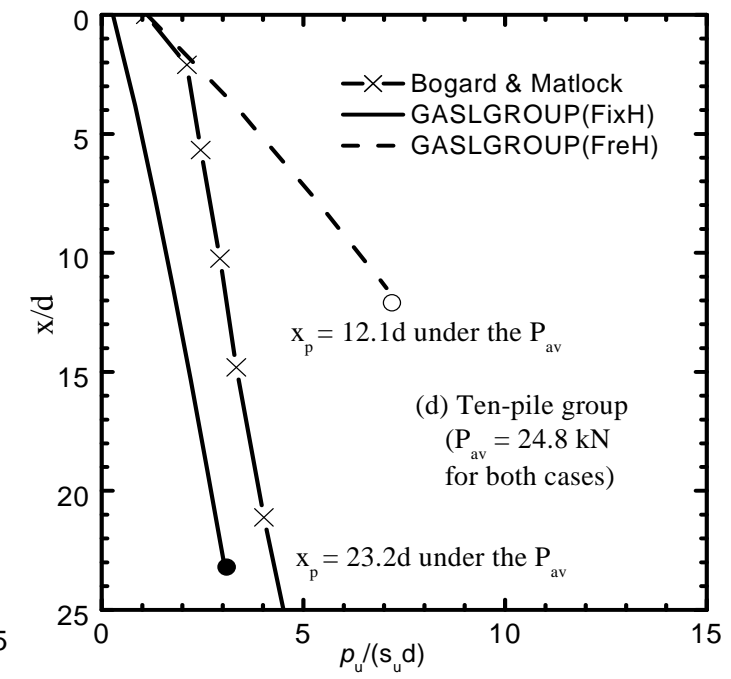

Figure 10. LFPs for the single pile, 5- and 10-pile groups [26]: Case III 

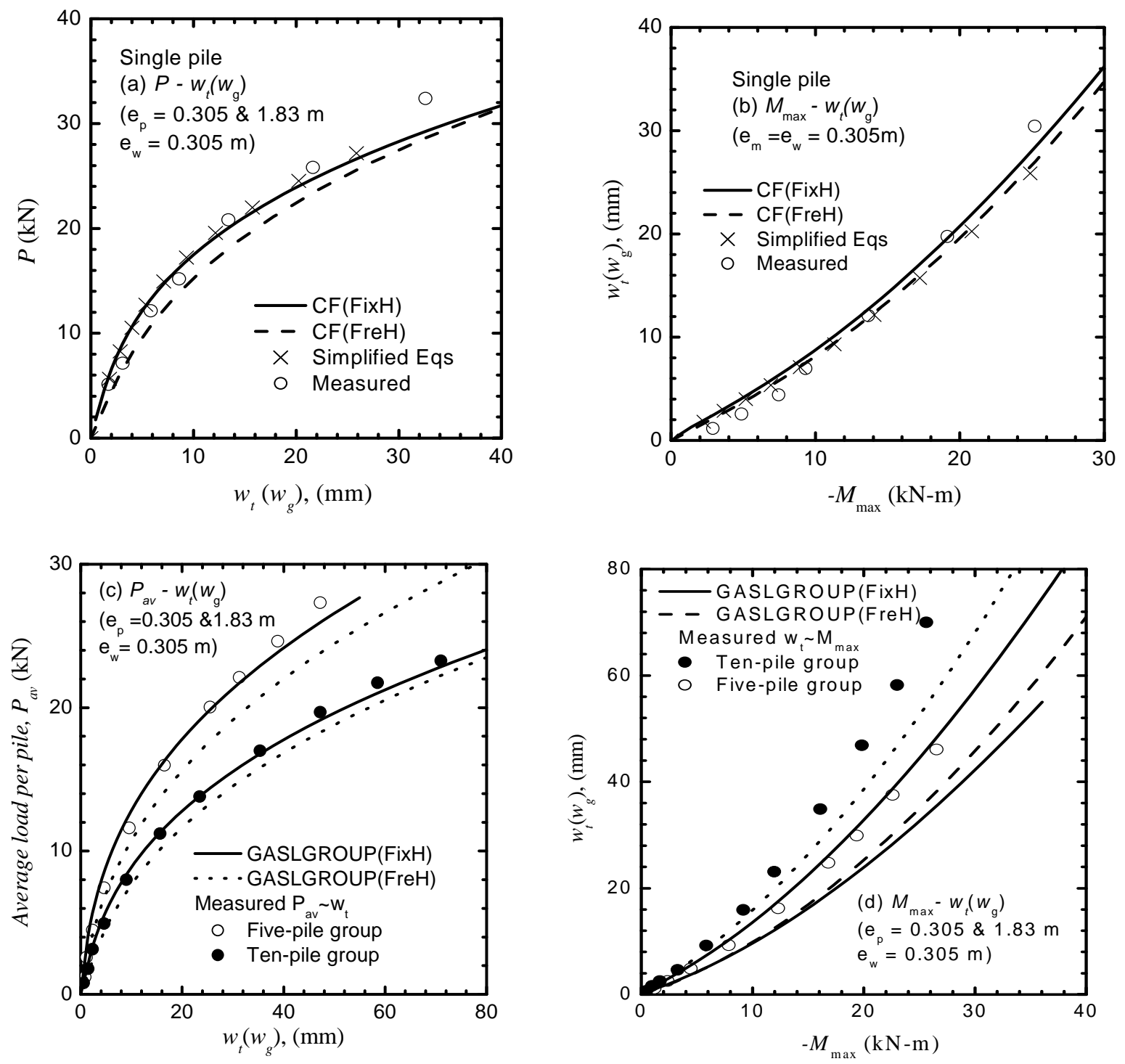

Figure 11. Predicted vs measured [26] response of single pile, 5- and 10-pile groups: Case III
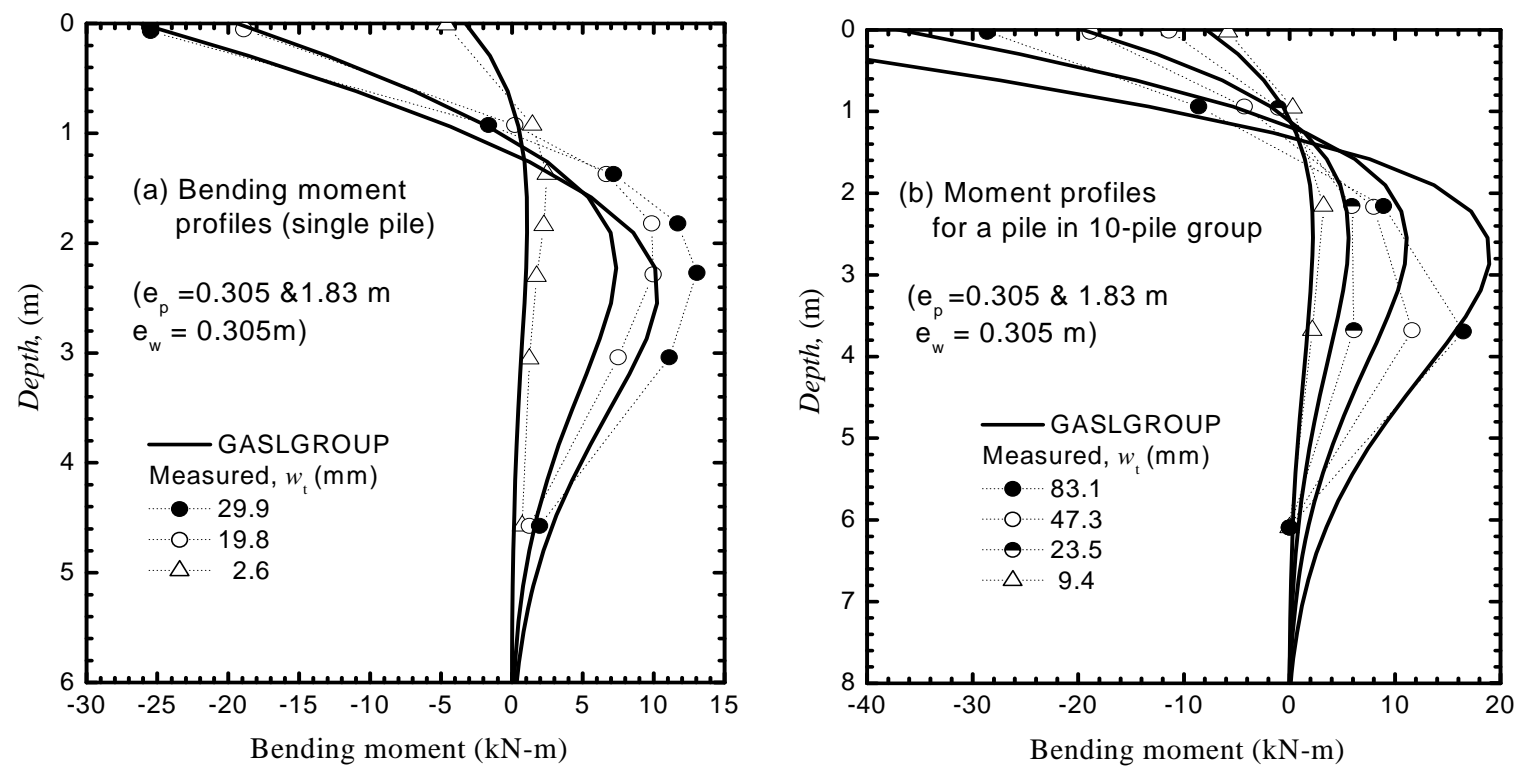

Figure 12 Predicted vs. measured [26] moment profiles of a pile in singular form and in 10-pile groups: Case III 

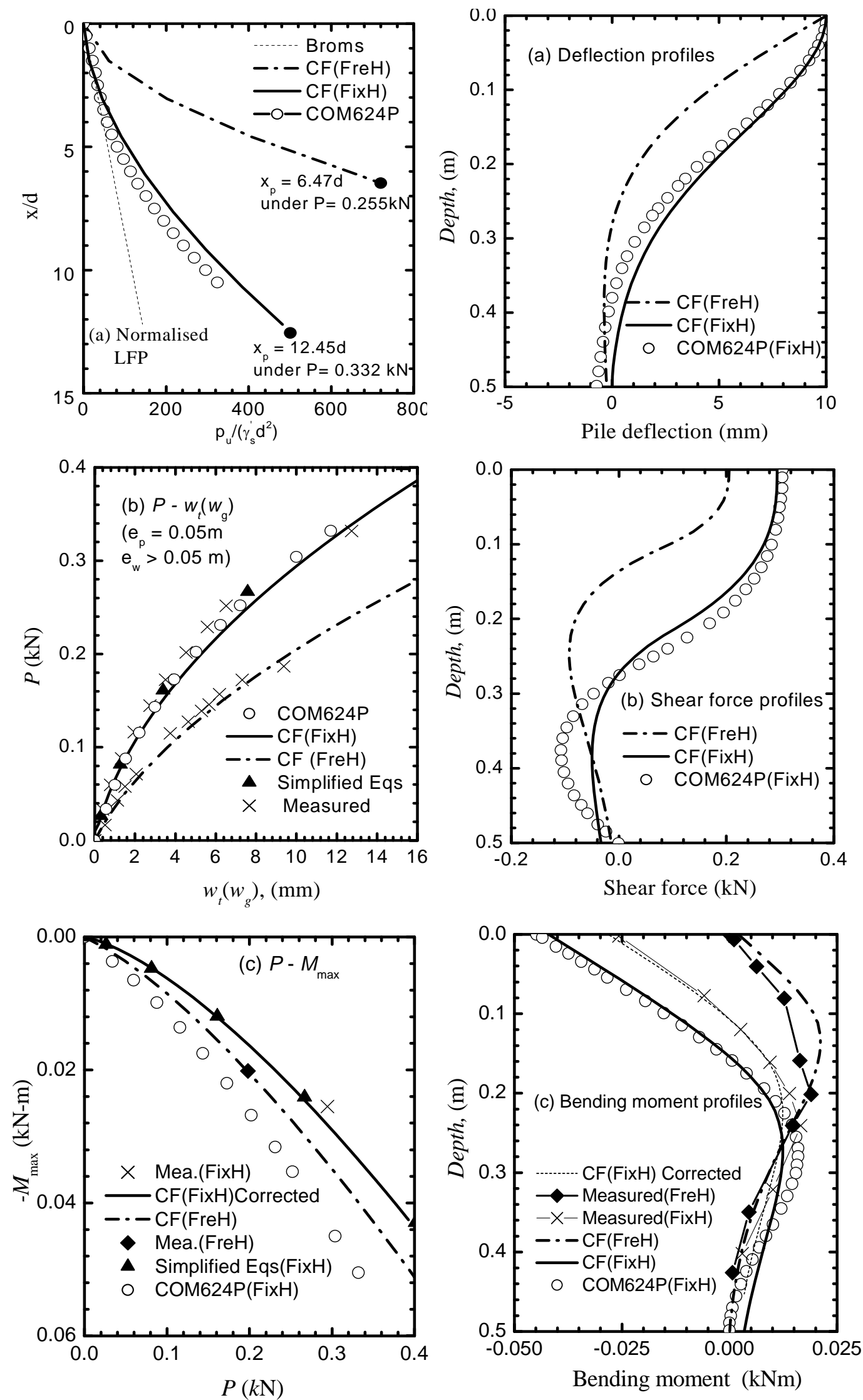

Figure 13. Predicted vs. measured [27] response of the driven piles: Case IV

Figure 14. Predicted vs. measured [27] response of the driven piles at $10 \mathrm{~mm}$ mudline deflection: Case IV 

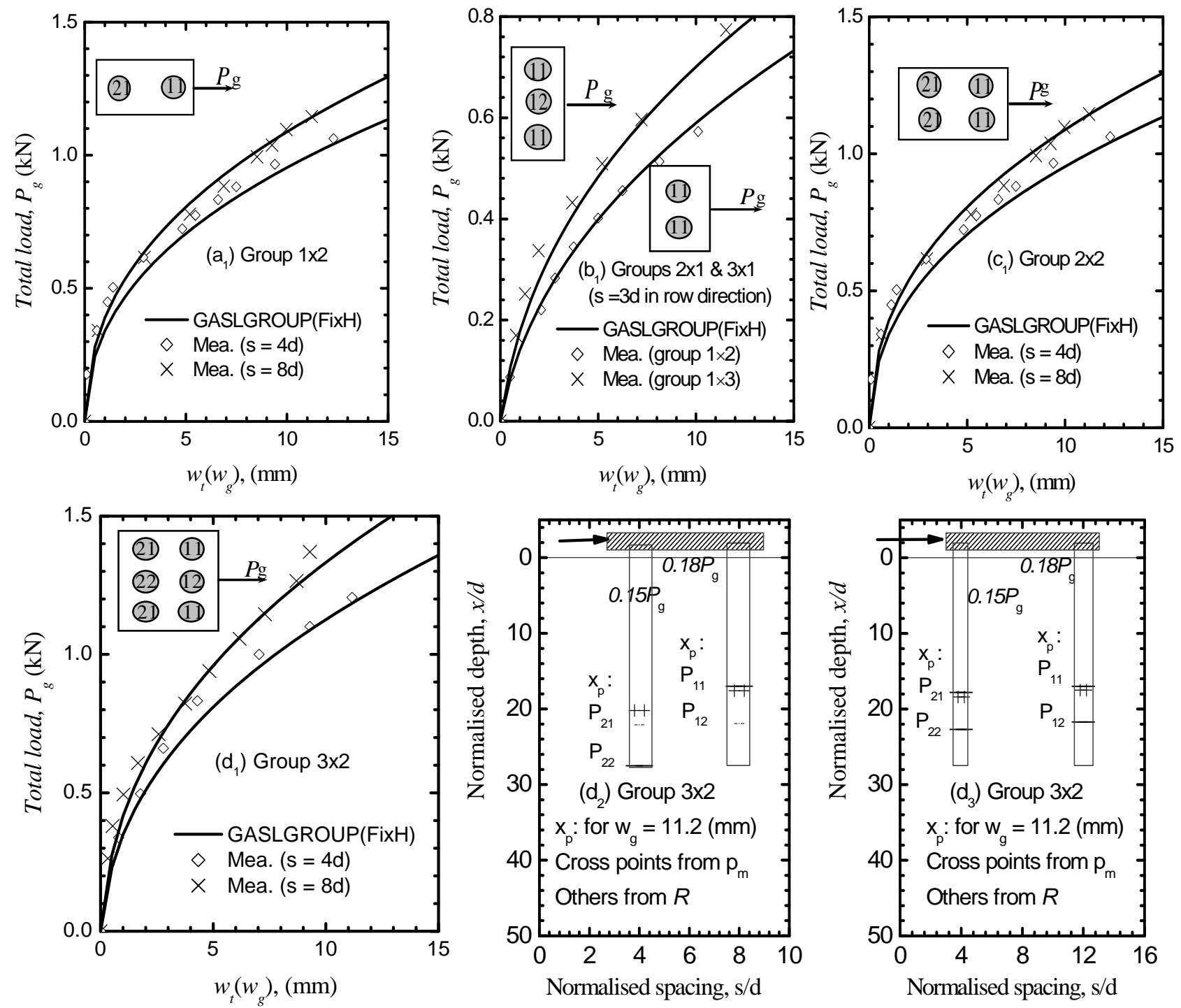

Figure 15. Predicted $P_{\mathrm{g}}-w_{\mathrm{g}}$ vs. measured [27] $P_{\mathrm{g}}-w_{\mathrm{t}}$ response of various groups: Case IV (2-rows) 

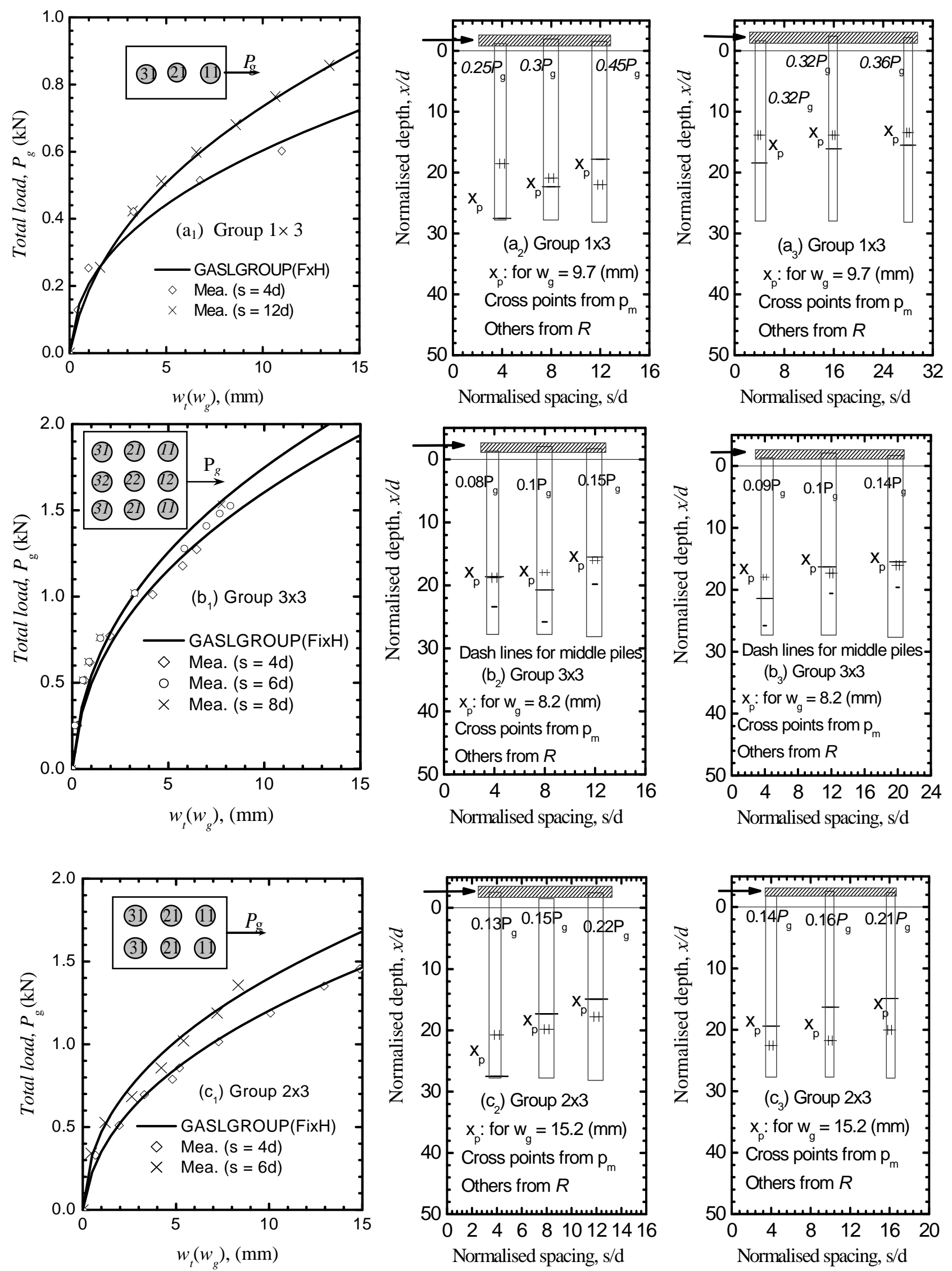

Figure 16. Predicted $P_{\mathrm{g}}-w_{\mathrm{g}}$ vs. measured [27] $P_{\mathrm{g}}-w_{\mathrm{t}}$ response of various groups: Case IV (3-rows) 